\title{
Novel pyrazole derivatives: Synthesis and evaluation of anti-angiogenic activity
}

\author{
Michael S. Christodoulou ${ }^{a}$, Sandra Liekens ${ }^{\text {b,* }}$, Konstantinos M. Kasiotis ${ }^{\text {a,c }}$, Serkos A. Haroutounian ${ }^{\text {a,* }}$ \\ ${ }^{\text {a } C h e m i s t r y ~ L a b o r a t o r y, ~ A g r i c u l t u r a l ~ U n i v e r s i t y ~ o f ~ A t h e n s, ~ I e r a ~ O d o s ~ 75, ~ A t h e n s ~ 11855, ~ G r e e c e ~}$ \\ ${ }^{\mathrm{b}}$ Rega Institute for Medical Research, Minderbroedersstraat 10, B-3000 Leuven, Belgium \\ ${ }^{\mathrm{c}}$ Benaki Phytopathological Institute, 8 St. Delta Street, Athens, Kifissia 14561, Greece
}

\section{A R T I C L E I N F O}

\section{Article history:}

Received 26 October 2009

Revised 21 March 2010

Accepted 26 April 2010

Available online 20 May 2010

\section{Keywords:}

Pyrazole

Pyrazolo[4,3-c]quinoline

Angiogenesis

Endothelial cell proliferation and migration

CAM assay

Inhibition of tumor growth

\begin{abstract}
A B S T R A C T
The synthesis of a series of novel trisubstituted pyrazole derivatives and their PIFA-mediated conversion to molecules bearing the fused pyrazolo[4,3-c]quinoline ring system is reported. The anti-angiogenic activity of these compounds was evaluated by using in vitro assays for endothelial cell proliferation and migration, and in the chicken chorioallantoic membrane (CAM) assay. Compounds containing the fused pyrazolo[4,3-c]quinoline motifs emerged as potent anti-angiogenic compounds, which also had the ability to inhibit the growth of human breast (MCF-7) and cervical (Hela) carcinoma cells in vitro.
\end{abstract}

(c) 2010 Elsevier Ltd. All rights reserved.

\section{Introduction}

Angiogenesis, the process of new blood vessel formation is pivotal for many physiological events including embryogenesis, organ development, the female reproductive cycle and wound healing. ${ }^{1,2}$ Under these conditions, angiogenesis is a highly regulated process, that is, turned on for brief periods and then completely inhibited. On the contrary, unregulated angiogenesis has been associated with the development of a diversity of disease states including cancer, retinopathy, rheumatoid arthritis, psoriasis, atherosclerosis and haemangioma. ${ }^{3-5}$

During the last decade several molecules containing various azaheterocyclic rings-including the pyrazole moiety ${ }^{6}$-in their structural framework have been considered, designed, synthesized and investigated as potent inhibitors of angiogenesis. ${ }^{7-9}$ Thus, in the course of our investigations concerning the exploitation of novel bioactive molecules containing the pyrazole residue, ${ }^{10,11}$ we envisioned the synthesis of novel fused pyrazolo[4,3-c]quinoline derivatives as potential anti-angiogenic agents. The rational to design these compounds was to combine in a single molecule the known pharmacophore quinoline ring with a substituted pyrazole ring backbone. This was achieved through the PIFA [phenyliodine(III) bis(trifluoroacetate) $]^{12}$ mediated ring closure of the appropriate trisubstituted pyrazole derivatives $\mathbf{6}$ to form the fused pyrazolo[4,3-c]quinoline ring system.

\footnotetext{
* Corresponding authors. Tel.: +30 2105294247; fax: +30 2105294265 (S.A.H.).

E-mail address: sehar@aua.gr (S.A. Haroutounian).
}

Various assays have been developed that recapitulate the different steps of the angiogenesis process, including endothelial cell proliferation, migration and tube formation in vitro. To study angiogenesis in vivo the most widely used assay is the chicken chorioallantoic membrane assay (CAM). ${ }^{13}$ In the present study, all novel compounds $(n=18)$ were evaluated for their capacity to inhibit endothelial cell proliferation. Based on this preliminary screening, two series of compounds were selected for further evaluation in an in vitro wound healing assay and the CAM assay. Finally, in order to determine whether the inhibitory activity of the compounds is specific for endothelial cells, we also investigated their potency to inhibit the growth of human cervical (Hela) and breast (MCF-7) carcinoma cells in vitro. Our data indicate that these novel pyrazole derivatives target both tumor and endothelial cells. In particular, the hydroxypyrazoloquinolin-4-ones emerged as potent antiangiogenic compounds, which may be used as lead compounds but also deserve further study in order to gain insight into their mechanism of action.

\section{Results}

\subsection{Chemistry}

The synthesis of hydroxypyrazolocarboxaldehydes 4 was accomplished in a three steps synthetic sequence as is outlined in Scheme 1. Specifically, the acetophenone substrates (1a-e) were condensed with 4-methoxyphenylhydrazine hydrochloride to produce hydrazines $\mathbf{2}$, which by subsequent treatment with the 
<smiles>[R]c1cc(-c2nn(-c3ccc(O)cc3)cc2C(=O)C=O)c([R5])c(-c2nn(-c3ccc(OC)cc3)cc2-c2cc([R4])c([R3])c([R])c2[R])c1</smiles>

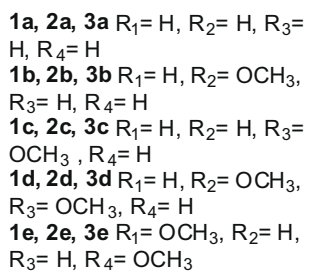

4a $\mathrm{R}_{5}=\mathrm{H}, \mathrm{R}_{6}=\mathrm{H}, \mathrm{R}_{7}=\mathrm{H}, \mathrm{R}_{8}=\mathrm{H}$ 4b $R_{5}=\mathrm{H}, \mathrm{R}_{6}=\mathrm{OH}, \mathrm{R}_{7}=\mathrm{H}, \mathrm{R}_{8}=\mathrm{H}$ 4c $\mathrm{R}_{5}=\mathrm{H}, \mathrm{R}_{6}=\mathrm{H}, \mathrm{R}_{7}=\mathrm{OH}, \mathrm{R}_{8}=\mathrm{H}$ 4d R $R_{5}=H, R_{6}=O H, R_{7}=O H, R_{8}=H$ $4 \mathrm{e} \mathrm{R}_{5}=\mathrm{OH}, \mathrm{R}_{6}=\mathrm{H}, \mathrm{R}_{7}=\mathrm{H}, \mathrm{R}_{8}=\mathrm{OH}$

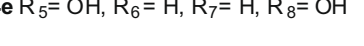

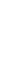

Scheme 1. Reagents and conditions: (a) 4-methoxyphenylhydrazine hydrochloride, acetic acid, $\mathrm{Et}_{3} \mathrm{~N}, \mathrm{EtOH}$; (b) $\mathrm{TCT}, \mathrm{DMF}$; (c) $\mathrm{BBr}_{3}, \mathrm{CH}_{2} \mathrm{Cl}_{2},-78{ }^{\circ} \mathrm{C}$.

iminium salt-produced from the reaction of 2,4,6-trichloro$[1,3,5]$ triazine (TCT, cyanuric chloride)-in DMF provided the core pyrazole backbone (compounds 3 ). Then, the subsequent removal of the methoxy protective groups with $\mathrm{BBr}_{3}$ at $-78^{\circ} \mathrm{C}$ afforded the hydroxy pyrazolocarboxaldehydes 4 .

Oxidation of the pyrazolocarboxaldehydes 3 with $\mathrm{NaOCl}_{2}$ at $0{ }^{\circ} \mathrm{C}$, in the presence of sulfamic acid as scavenger, furnished quantitatively the corresponding acids $\mathbf{5}$, which were treated with methoxylamine hydrochloride in the presence of the uronium-coupling reagent TBTU to provide amides $\mathbf{6}$. The latter were cyclized by a nucleophilic substitution reaction, which was promoted by PIFA that served as the source of hypervalent iodine and trifluoroacetic acid (TFA) as additive, to furnish the target pyrazoloquinolin-4-one fused ring system 7 . Finally, the removal of the methoxy protective groups with $\mathrm{BBr}_{3}$ at $-78{ }^{\circ} \mathrm{C}$ afforded the desired hydroxypyrazoloquinolin-4-ones 8 (Scheme 2).<smiles>[R]c1cc(-c2nn(-c3ccc(OC)cc3)cc2C=O)c([R])c([R])c1[R]</smiles><smiles>[R4]c1cc(-c2nn(-c3ccc(OC)cc3)cc2C(=O)O)c([R7])c([R])c1[R]</smiles><smiles>[R]c1cc(-c2nn(-c3ccc(OC)cc3)cc2C(=O)NOC)c([R])c([R4])c1[R]</smiles><smiles>[R]c1c([R8])c([R8])c2c(c1[R])c1nn(-c3ccc(O)cc3)cc1c(=O)n2O</smiles><smiles>[R]c1c([R])c([R])c2c(c1[R])c1nn(-c3ccc(OC)cc3)cc1c(=O)n2OC</smiles>

3a, 5a, 6a, 7a R $1=H, R_{2}=H$, $\mathrm{R}_{3}=\mathrm{H}, \mathrm{R}_{4}=\mathrm{H}$

3b, 5b, 6b, 7b R $\mathrm{R}_{1}=\mathrm{H}, \mathrm{R}_{2}=$ $\mathrm{OCH}_{3}, \mathrm{R}_{3}=\mathrm{H}, \mathrm{R}_{4}=\mathrm{H}$ 3c, 5c, 6c, 7c R $\mathrm{R}_{1}=\mathrm{H}, \mathrm{R}_{2}=\mathrm{H}$ $\mathrm{R}_{3}=\mathrm{OCH}_{3}, \mathrm{R}_{4}=\mathrm{H}$ 3d, 5d, 6d, 7d R $R_{1}=H, R_{2}=$ $\mathrm{OCH}_{3}, \mathrm{R}_{3}=\mathrm{OCH}_{3}, \mathrm{R}_{4}=\mathrm{H}$ 3e, 5e, 6e, 7e R $\mathrm{R}_{1}=\mathrm{OCH}_{3}, \mathrm{R}_{2}=$ $\mathrm{H}, \mathrm{R}_{3}=\mathrm{H}, \mathrm{R}_{4}=\mathrm{OCH}_{3}$

8a $\mathrm{R}_{5}=\mathrm{H}, \mathrm{R}_{6}=\mathrm{H}, \mathrm{R}_{7}=\mathrm{H}, \mathrm{R}_{8}=\mathrm{H}$ 8b $R_{5}=\mathrm{H}, \mathrm{R}_{6}=\mathrm{OH}, \mathrm{R}_{7}=\mathrm{H}, \mathrm{R}_{8}=\mathrm{H}$ 8c $\mathrm{R}_{5}=\mathrm{H}, \mathrm{R}_{6}=\mathrm{H}, \mathrm{R}_{7}=\mathrm{OH}, \mathrm{R}_{8}=\mathrm{H}$ 8d $\mathrm{R}_{5}=\mathrm{H}, \mathrm{R}_{6}=\mathrm{OH}, \mathrm{R}_{7}=\mathrm{OH}, \mathrm{R}_{8}=\mathrm{H}$ $8 \mathrm{e} \mathrm{R}_{5}=\mathrm{OH}, \mathrm{R}_{6}=\mathrm{H}, \mathrm{R}_{7}=\mathrm{H}, \mathrm{R}_{8}=\mathrm{OH}$

Scheme 2. Reagents and conditions: (a) $\mathrm{NaClO}_{2}, \mathrm{H}_{2} \mathrm{NSO}_{3} \mathrm{H}$, acetone $/ \mathrm{H}_{2} \mathrm{O}, 0{ }^{\circ} \mathrm{C}$; (b) $\mathrm{Et}_{3} \mathrm{~N}, \mathrm{NH}_{2} \mathrm{OMe} \cdot \mathrm{HCl}, \mathrm{TBTU}, \mathrm{MeCN}$; (c) $\mathrm{PIFA}, \mathrm{TFA}, \mathrm{CH}_{2} \mathrm{Cl}{ }_{2}$; (d) $\mathrm{BBr} 3, \mathrm{CH}_{2} \mathrm{Cl}{ }_{2},-78{ }^{\circ} \mathrm{C}$. 

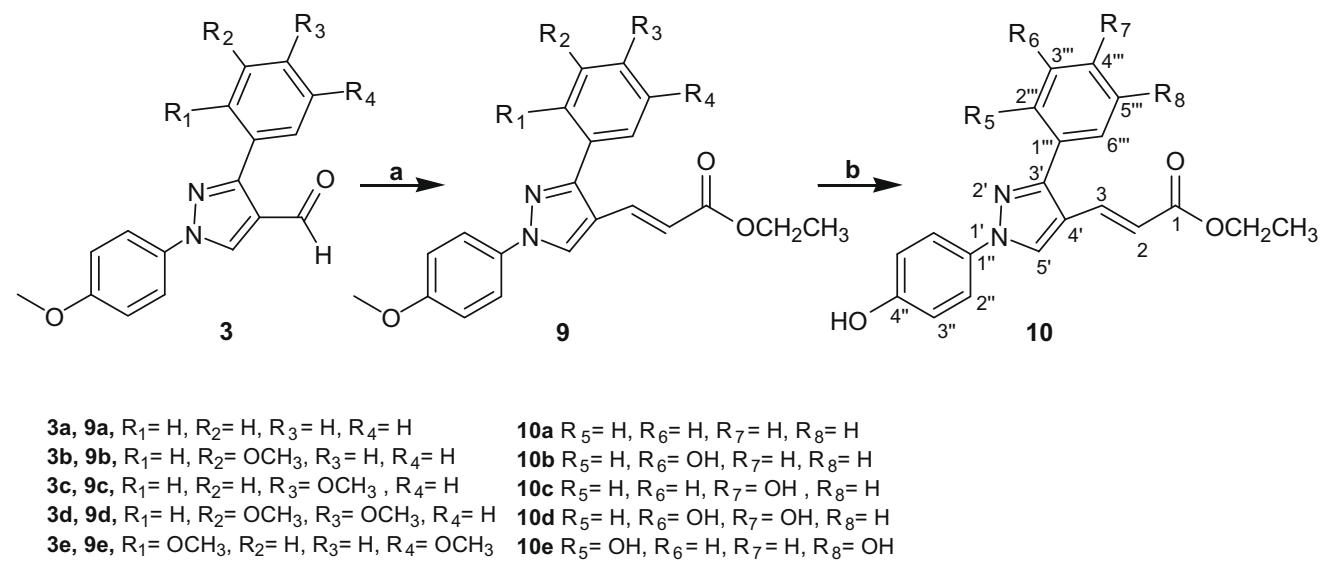

Scheme 3. Reagents and conditions: (a) $\mathrm{Ph}_{3} \mathrm{PCHCO}_{2} \mathrm{CH}_{2} \mathrm{CH}_{3}$, MeCN, reflux; (b) $\mathrm{BBr}_{3}, \mathrm{CH}_{2} \mathrm{Cl}_{2},-78{ }^{\circ} \mathrm{C}$.

The synthesis of esters $\mathbf{9}$ was accomplished through the Wittig reaction of pyrazolocarboxaldehydes $\mathbf{3}$ with the stabilized ylide $\mathrm{Ph}_{3} \mathrm{PCHCO}_{2} \mathrm{CH}_{2} \mathrm{CH}_{3}$ which formed in very good yields the desirable $E$-isomer of the corresponding esters $\mathbf{9}$. Demethylation of esters $\mathbf{9}$ with $\mathrm{BBr}_{3}$ at $-78^{\circ} \mathrm{C}$ afforded the desired unprotected esters $\mathbf{1 0}$ (Scheme 3).

Finally, esters 9 were hydrolyzed almost quantitatively to acids 11, which were subsequently demethylated at $-78^{\circ} \mathrm{C}$, in the presence of $\mathrm{BBr}_{3}$, to produce derivatives $\mathbf{1 2}$ (Scheme 4).

\subsection{Biological activity}

\subsubsection{Inhibition of endothelial cell proliferation by pyrazole derivatives}

In order to evaluate the anti-angiogenic activity of the pyrazole derivatives, we first assessed their in vitro effect (Table 1) on the proliferation of mouse aortic endothelial cells (MAEC).

Several compounds elicited a dose-dependent inhibition of endothelial cell proliferation with $50 \%$ inhibitory concentrations $\left(\mathrm{IC}_{50}\right)$ ranging from 6 to $44 \mu \mathrm{M}$. Among the hydroxypyrazolocarboxaldehydes, compound 4d proved to be the most potent exhibiting an $\mathrm{IC}_{50}$ of $12 \mu \mathrm{M}$, whereas $4 \mathrm{a}$ did not inhibit endothelial cell proliferation ( $\mathrm{IC}_{50}$ higher than $100 \mu \mathrm{M}$ ). The replacement of their aldehyde group with an alkylated ester $(\mathbf{1 0 a - 1 0 e})$ resulted in a slight improvement of their anti-proliferative activities, displaying $\mathrm{IC}_{50}$ values between 6 and $29 \mu \mathrm{M}$. On the contrary, hydrolysis of the esters and their subsequent demethylation to the corresponding acids (12a-12e) rendered the compounds inactive ( $\mathrm{IC}_{50}$ $>100 \mu \mathrm{M})$.
Table 1

Cytostatic activity of novel pyrazole derivatives in MAEC (mouse aortic endothelial cells).

\begin{tabular}{llllll}
\hline Aldehydes & $\mathbf{4 a}$ & $\mathbf{4 b}$ & $\mathbf{4 c}$ & $\mathbf{4 d}$ & $\mathbf{4 e}$ \\
\hline $\mathrm{IC}_{50}{ }^{\mathrm{a}}$ & $\geqslant 100$ & $42 \pm 3.4$ & $44 \pm 7.2$ & $12 \pm 2.9$ & $43 \pm 15$ \\
Closed rings & $\mathbf{8 a}$ & $\mathbf{8 b}$ & $\mathbf{8 c}$ & & \\
$\mathrm{IC}_{50}{ }^{\mathrm{a}}$ & $7.0 \pm 0.3$ & $25 \pm 1.4$ & $42 \pm 4.2$ & & \\
Esters & $\mathbf{1 0 a}$ & $\mathbf{1 0 b}$ & $\mathbf{1 0 c}$ & $\mathbf{1 0 d}$ & $\mathbf{1 0 e}$ \\
$\mathrm{IC} \mathrm{C}_{50}{ }^{\mathrm{a}}$ & $29 \pm 15$ & $14 \pm 0.6$ & $25 \pm 1.1$ & $6.2 \pm 1.3$ & $12 \pm 2.8$ \\
Acids & $\mathbf{1 2 a}$ & $\mathbf{1 2 b}$ & $\mathbf{1 2 c}$ & $\mathbf{1 2 d}$ & $\mathbf{1 2 e}$ \\
$\mathrm{IC}_{50}{ }^{\mathrm{a}}$ & $>100$ & $>100$ & $>100$ & $>100$ & $>100$ \\
\hline
\end{tabular}

a Data are expressed as micromolar concentrations.

Comparison of compounds activities within each series indicated that the presence of two hydroxyl groups in meta and para positions of the B-phenyl moiety (compounds d) increased their anti-proliferative activities. On the other hand, the ring closure of compounds 4 to produce the hydroxypyrazoloquinolin-4-ones 8 potentiated the cytostatic effect of the compounds, with $8 \mathbf{a}$ being the most active compound of this series ( $\mathrm{IC}_{50}$ of $7 \mu \mathrm{M}$ ).

\subsubsection{Inhibition of endothelial cell migration by pyrazole derivatives}

Endothelial cell migration is an essential step in the formation of new blood vessels. In order to further evaluate the in vitro anti-angiogenic activity of the pyrazole derivatives, we focused on compounds $\mathbf{4}$ and $\mathbf{8}$ (Fig. 1). The hydroxypyrazolocarboxaldehydes $\mathbf{4 b}$ and in particular $\mathbf{4 d}$ significantly inhibited wound closure of<smiles>[R]c1cc(-c2nn(-c3ccc(OC)cc3)cc2/C=C/C(=O)OCC)c([R])c([R])c1[R]</smiles>

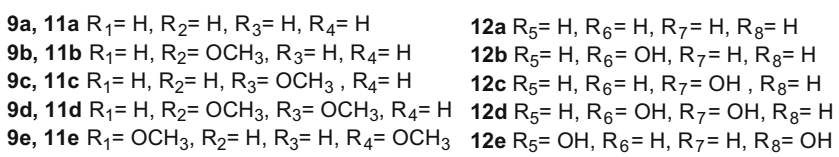




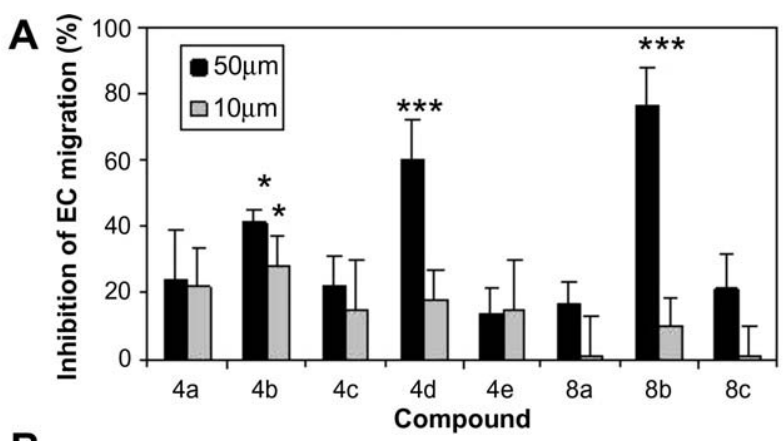

B
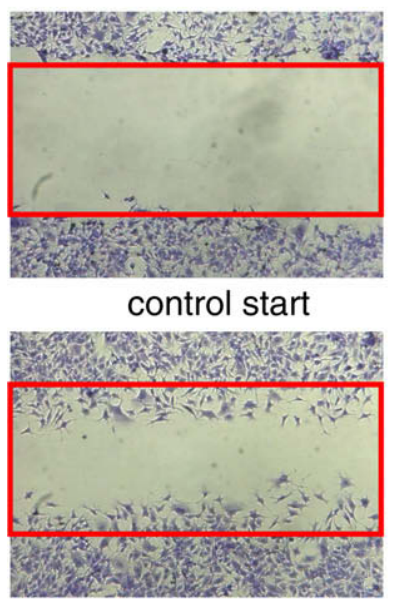

$4 \mathrm{~d}(50 \mu \mathrm{M})$ control start

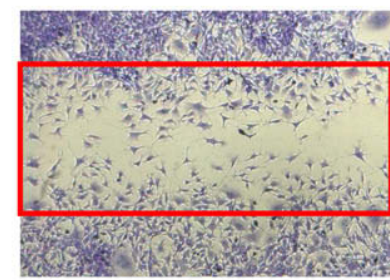

control

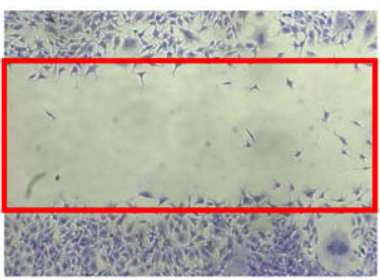

$8 \mathrm{~b}(50 \mu \mathrm{M})$
Figure 1. Effects of hydroxypyrazolocarboxaldehydes (4d) and hydroxypyrazoloquinolin-4-ones $(\mathbf{8 b})$ on endothelial wound repair. Confluent MAEC were wounded with a $1.0 \mathrm{~mm}$ wide tip and incubated with two concentrations $(10$ and $50 \mu \mathrm{M})$ of the test compounds. After $8 \mathrm{~h}$, the wounds were photographed and endothelial cells invading the wound were quantified by computerized analysis of the digitalized pictures, Results are expressed as mean \pm SEM. ${ }^{*} p<0.05$, ${ }^{* * *} p<0.01$ (A). (B) Representative images of control monolayers at 0 and $8 \mathrm{~h}$ after wounding. Compounds $\mathbf{4 d}$ and $\mathbf{8 b}$ significantly delayed wound healing at $50 \mu \mathrm{M}$.

the endothelial cells at $50 \mu \mathrm{M}$. However, the most potent inhibitor of endothelial cell migration was hydroxypyrazoloquinolin-4-one 8b, which showed $76 \%$ inhibition at $50 \mu \mathrm{M}$.

\subsubsection{Inhibition of angiogenesis in the CAM assay}

Next, the anti-angiogenic activity of the compounds was evaluated in the CAM assay, which represents the most widely used assay to study angiogenesis in vivo. In this regard we used SU5416 (Fig. 3), a well-established anti-angiogenic agent, which inhibits vascular endothelial growth factor (VEGF), as a positive control. ${ }^{14}$ At $50 \mathrm{nmol} / \mathrm{CAM}$, this compound elicited $54 \%$ inhibition of angiogenesis $(p<0.01)$. Compound $4 a$ did not show a significant antiangiogenic activity at this concentration. However, $\mathbf{4 b}$ and $\mathbf{4 c}$ inhibited blood vessel formation by respectively $50 \%$ and $48 \%$ ( $p$ $<0.05$ ) (Fig. 2). Compounds $4 \mathbf{d}$ and $\mathbf{4 e}$ induced an inflammatory response in the CAM, which made an evaluation of angiogenesis impossible. All compounds of $\mathbf{8}$ series significantly inhibited blood vessel formation in the CAM, with compound $\mathbf{8 b}$ being the most potent one, eliciting $64 \%$ of inhibition ( $p<0.01$, Fig. 2 ). It should be noted however, that a $100 \%$ inhibition of angiogenesis cannot be achieved by this method, since the pre-existing vessels-already present at day 9 when the compounds are put on the CAM-are also being counted when angiogenesis is assessed at day 11 . Thus, 8b nearly completely inhibited the formation of new blood vessels, as shown in Figure 2B. In fact, the assessed activity of this compound is comparable with the reference anti-angiogenic molecule SU5416.

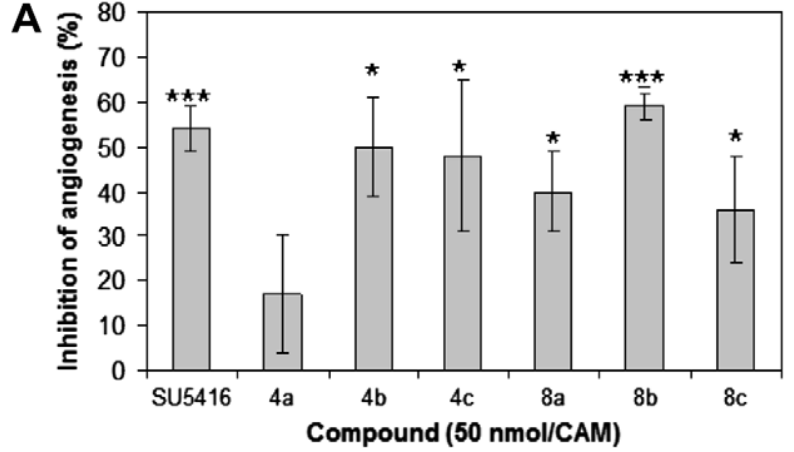

B

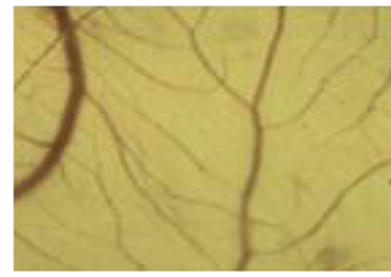

control

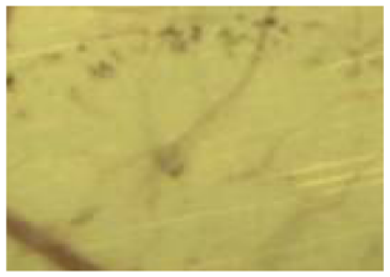

$8 b$
Figure. 2. Effects of hydroxypyrazolocarboxaldehydes (4) and hydroxypyrazoloquinolin-4-ones (8) on angiogenesis in the CAM assay. At day 9 of incubation, discs containing either $50 \mathrm{nmol}$ of the test compounds or SU5416 were applied onto the CAM. A control disc containing an equal amount of solvent (DMSO) was positioned on the CAM $1 \mathrm{~cm}$ away from the test compounds. At day 11, the percentage of inhibition of blood vessel formation, compared to untreated controls, was determined (see materials and methods). Results are expressed as mean \pm SEM. ${ }^{*} p<0.05$; ${ }^{* * *} p<0.01$ (A). (B) CAMs treated with a control disc are characterized by extensive neovascularization, whereas a large avascular zone is visible in CAMs treated with $\mathbf{8 b}$

\subsubsection{Inhibition of tumor cell proliferation by pyrazole derivatives}

Next, we investigated if the inhibitory activity of the compounds examined is specific for endothelial cells and whether these compounds also affect tumor cell proliferation. Therefore, the anti-proliferative activity of hydroxyl pyrazolocarboxaldehydes $\mathbf{4}$ and hydroxyyrazoloquinolin-4-ones $\mathbf{8}$ was compared in MAEC (see also Table 1), bovine aortic endothelial cells (BAEC), and the human cervical (Hela) and breast carcinoma (MCF-7) cells. All compounds showed comparable activity in the endothelial and tumor cell lines (Table 2).

\section{Discussion}

Several literature studies have provided evidences that pyrazole derivatives inhibit angiogenesis by interacting with various molecular targets. In addition, these compounds may combine antiangiogenic and direct anti-tumor activities. More specifically, pyrazole derivatives were found to inhibit the proliferation of endothelial cells and angiogenesis in a matrigel plug assay by blocking the intermediate-conductance $\mathrm{Ca}^{2+}$-activated $\mathrm{K}^{+}$channel (IKCa1). ${ }^{15}$ It was hypothesized that an upregulation of the expression of IKCa1 by angiogenic factors, such as basic fibroblast growth factor (FGF2) and vascular endothelial growth factor (VEGF) is required to stimulate endothelial cell proliferation and angiogenesis in vivo. Thus, selective IKCa1 blockers might inhibit angiogenesis by interfering with growth factor activity.

Pyrazole derivatives were also identified as antagonists of the integrin $\alpha_{v} \beta_{3}$, which is upregulated on endothelial cells during angiogenesis. ${ }^{16}$ These integrin antagonists were shown to inhibit angiogenesis in the mouse corneal pocket model.

Another class of pyrazoles (3,4-diaryl pyrazole resorcinol derivatives) was identified to inhibit the heat-shock protein HSP90. Thus, the reference compound CCT018159 (Fig. 3) was shown to 

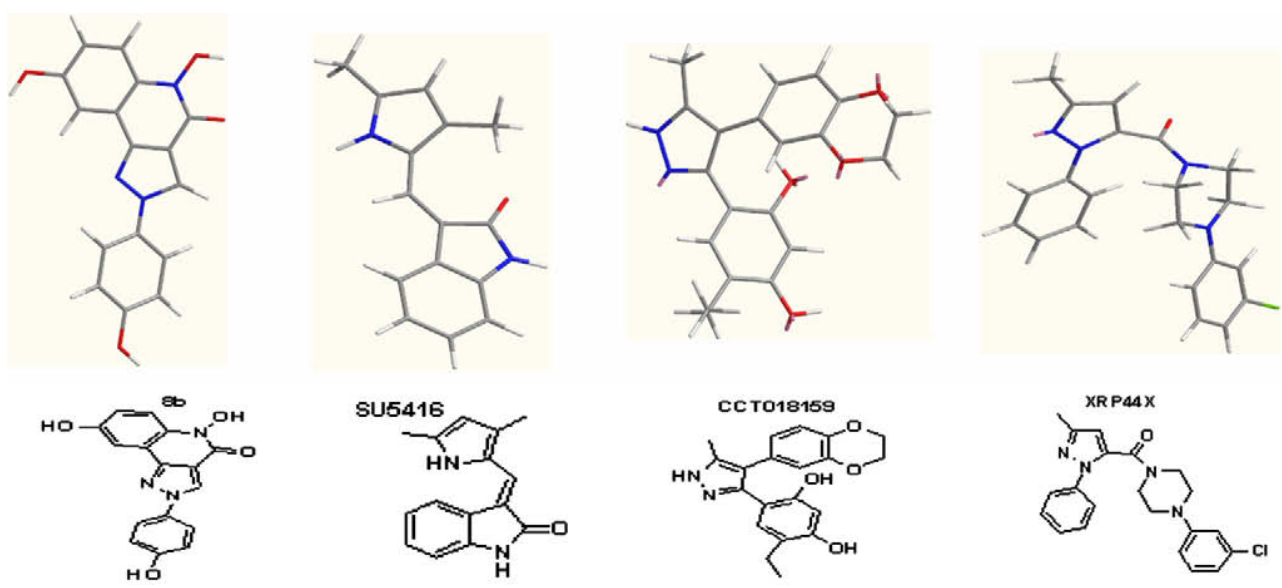

Figure 3. 3D chemical structures of compound $\mathbf{8 b}$ and reference compounds SU5416, CCT018159 and XRP44X.

Table 2

Cytostatic activity of compounds $\mathbf{4}$ and $\mathbf{8}$ in endothelial and tumor cell lines

\begin{tabular}{lllll}
\hline \multirow{2}{*}{ Compound } & \multicolumn{4}{c}{$\mathrm{IC}_{50}{ }^{\mathrm{a}}(\mu \mathrm{M})$} \\
\cline { 2 - 5 } & MAEC & BAEC & Hela & MCF-7 \\
\hline 4a & $\geqslant 100$ & $64 \pm 8.4$ & $79 \pm 8.8$ & $47 \pm 5.1$ \\
$\mathbf{4 b}$ & $42 \pm 3.4$ & $29 \pm 4.5$ & $37 \pm 4.9$ & $29 \pm 6.8$ \\
$\mathbf{4 c}$ & $44 \pm 7.2$ & $32 \pm 8.7$ & $37 \pm 9.5$ & $38 \pm 6.0$ \\
$\mathbf{4 d}$ & $12 \pm 2.9$ & $17 \pm 4.2$ & $39 \pm 1.4$ & $24 \pm 0.4$ \\
$\mathbf{4 e}$ & $43 \pm 15$ & $\geqslant 100$ & $\geqslant 100$ & $\geqslant 100$ \\
$\mathbf{8 a}$ & $7.0 \pm 0.25$ & $4.6 \pm 0.9$ & $8.9 \pm 0.1$ & $5.8 \pm 1.8$ \\
$\mathbf{8 b}$ & $25 \pm 1.4$ & $38 \pm 9.1$ & $37 \pm 2.6$ & $26 \pm 2.2$ \\
$\mathbf{8 c}$ & $42 \pm 4.2$ & $52 \pm 11$ & $38 \pm 4.3$ & $25 \pm 8.1$ \\
\hline
\end{tabular}

${ }^{\mathrm{a}} \mathrm{IC}_{50}=$ concentration of compound that reduces cell proliferation by $50 \%$.

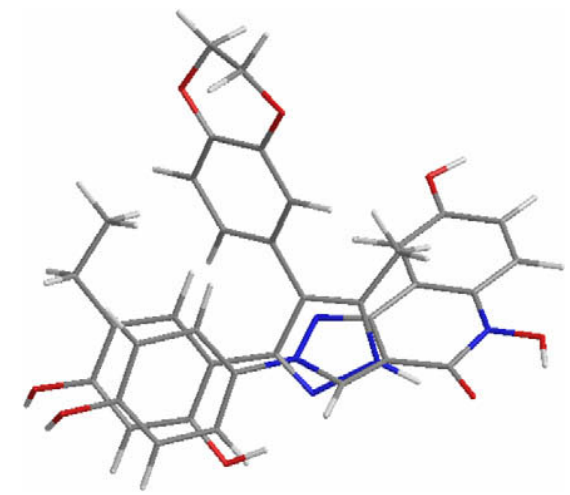

Figure 4. Superimposition of the $3 \mathrm{D}$ chemical structure of compound $\mathbf{8 b}$ and the anti-angiogenic pyrazole derivative CCT018159.

inhibit cell proliferation by inducing G1 arrest and apoptosis. CCT018159 also inhibited both endothelial and tumor cell functions implicated in invasion and angiogenesis. ${ }^{17}$

Finally, pyrazole XRP44X (Fig. 3) has found to inhibit FGF2-induced activation of the Ras-Net (Elk-3) signaling pathway. ${ }^{18}$ XRP44X also abrogated cell growth, cell cycle progression and in vitro angiogenesis. In addition, this compound binds to the colchicine-binding site of tubulin, resulting in depolymerization of the microtubules and affects the actin cytoskeleton. These data indicate that XRP44X may combine anti-angiogenic and vasculartargeting properties.

The herein reported compounds share several structural similarities with the aforementioned lead compounds containing a fused rigid backbone that combines in a single molecule the substituted pyrazole ring and the pharmacophore quinoline in the form of novel fused pyrazole-quinolin-4-one derivatives. Figures 3 and 4 delineate the structural similarities of pyrazole $\mathbf{8 b}$ with the corresponding lead molecules.

of 18 novel pyrazole derivatives synthesized and studied, we have identified several compounds that inhibit endothelial cell proliferation. Two classes of compounds (hydroxypyrazolocarboxaldehydes and hydroxyl pyrazoloquinolin-4-ones) were selected for further investigation. Compound $\mathbf{8 b}$-bearing the fused pyrazolo[4,3-c]quinoline structural motif-emerged as a promising lead compound, with inhibitory activity against endothelial and tumor cell proliferation in vitro and angiogenesis in vivo.

Therefore, further studies should aim at determining the mechanism of action of this compound as well as its potential anti-tumor activity in vivo.

\section{Experimental}

\subsection{General experimental conditions}

All reactions were carried out in oven-dried glassware under argon atmosphere. All starting materials were purchased from Aldrich, while the solvents used were purified by distillation prior to use. Solvent mixtures employed in chromatography were reported as volume to volume ratios. Thin layer chromatography (TLC) was performed on Merck precoated aluminium sheets of Silica Gel $60 \mathrm{~F}_{254}$, visualization of products being accomplished by UV absorbance at $254 \mathrm{~nm}$ and by an alcohol solution of anisaldehyde with heating. Flash column chromatography was performed on a SDS silica gel $(35-70 \mu \mathrm{m})$. Melting points were determined on a Stuart apparatus (SMP3) and are uncorrected. IR spectra were recorded on a Thermo electron corporation Nicolet 6700 FT-IR spectrometer using $\mathrm{CH}_{2} \mathrm{Cl}_{2}$ in $\mathrm{ZnSe}$ round windows. ${ }^{1} \mathrm{H} \mathrm{NMR}$ and ${ }^{13} \mathrm{C}$ NMR spectra were recorded at 400 and $50 \mathrm{MHz}$ respectively on Bruker DRX-400 and DRX-200 spectrometers in the indicated solvents. Chemical shifts $(\delta)$ for proton and carbon resonances are quoted in parts per million (ppm) relative to tetramethylsilane (TMS), which was used as an internal standard. MS spectra were recorded using electrospray ionisation (ESI) technique on a Thermo Accela LC TSQ Quantum Access MS-MS spectometer.

\subsection{Synthesis}

4.2.1. Typical procedure for the synthesis of hydrazines $2 \mathrm{a}-\mathrm{c}$ 4.2.1.1. Synthesis of 1-(4'-methoxyphenyl)-2-(1"-phenylethylidene) hydrazine (2a). To a stirred solution of acetophenone 1a $(2.4 \mathrm{~mL}, 20 \mathrm{mmol})$ in $35 \mathrm{~mL}$ of ethanol and acetic acid $(1.5 \mathrm{~mL})$, a 
solution of 4-methoxyphenylhydrazine hydrochloride (4.3 g, $24 \mathrm{mmol}$ ) and $\mathrm{Et}_{3} \mathrm{~N}(4.2 \mathrm{~mL}, 30 \mathrm{mmol})$ in $40 \mathrm{~mL}$ of ethanol was added. The reaction mixture was stirred overnight at room temperature and the resulting precipitate was filtered and washed with ethanol and diethylether to produce the hydrazine product $\mathbf{2 a}$ as white solid (95\% yield). IR (film) $v: 3343 \mathrm{~cm}^{-1} ;{ }^{1} \mathrm{H}$ NMR (DMSO): $\delta=9.07(1 \mathrm{H}, \mathrm{s}, \mathrm{NH}), 7.78(2 \mathrm{H}, \mathrm{d}, J 7.6 \mathrm{~Hz}, \mathrm{H}-2$ "' and H-6"'), 7.38 (2H, t, J 7.2 Hz, H-3"' and H-5"'), 7.28 (1H, t, J 7.2 Hz, H-4"'), 7.19 (2H, d, J 8.4 Hz, H-2'), 6.86 (2H, d, J $8.8 \mathrm{~Hz}, \mathrm{H}-3$ '), 3.70 (3H, s, $\mathrm{OCH}_{3}$ ), 2.23 (3H, s, H-2"); ${ }^{13} \mathrm{C}$ NMR (DMSO): $\delta=153.1$ (C-4'), 140.6 (C-1"), 139.8 (C-1"' and C-1'), 128.7 (C-3"' and C-5"'), 127.7 (C-4"'), 125.4 (C-2"' and C-6"'), 114.8 (C-2'), 114.3 (C-3'), $55.68\left(\mathrm{C}-\mathrm{OCH}_{3}\right), 13.11$ (C-2"); MS: $241.29\left(\mathrm{M}+\mathrm{H}^{+}\right)$. Anal. Calcd for $\mathrm{C}_{15} \mathrm{H}_{16} \mathrm{~N}_{2} \mathrm{O}$ : C, 74.97; $\mathrm{H}$, $6.71 ; \mathrm{N}, 11.66$. Found: $\mathrm{C}, 74.78 ; \mathrm{H}, 6.58 ; \mathrm{N} 11.82$.

4.2.1.2. 1-(4'-Methoxyphenyl)-2-(1"-(3"'-methoxyphenyl) ethylidene) hydrazine (2b). According to the typical procedure, hydrazine $\mathbf{2 b}$ was obtained from acetophenone $\mathbf{1 b}$ as white solid $(95 \%$ yield). IR (film) $v: 3345 \mathrm{~cm}^{-1} ;{ }^{1} \mathrm{H}$ NMR (DMSO): $\delta=9.09(1 \mathrm{H}, \mathrm{s}$, $\mathrm{NH}), 7.34-7.30(2 \mathrm{H}, \mathrm{m}, \mathrm{H}-4$ "' and H-6"'), $7.27(1 \mathrm{H}, \mathrm{t}, J 7.6 \mathrm{~Hz}$, H-5"'), 7.18 (2H, d, J $8.8 \mathrm{~Hz}, \mathrm{H}-2$ '), 6.86-6.82 (3H, m, H-2"' and $\left.\mathrm{H}-3^{\prime}\right), 3.78$ (3H, s, C3'"'-OCH $), 3.68$ (3H, s, C4'-OCH $\mathrm{OCH}_{3}, 2.20$ (3H, s, H-2"); ${ }^{13}$ C NMR (DMSO): $\delta=159.7$ (C-3"'), 153.1 (C-4'), 141.3 (C1"), 140.6 (C-1'), 139.5 (C-1"'), 129.7 (C-5”'), 118.0 (C-6"'), 114.8 (C-2'), 114.2 (C-3'), 113.1 (C-4"'), 110.8 (C-2”'), 55.6 (C4'-OCH ${ }^{3}$, $55.4\left(\mathrm{C}^{\prime \prime \prime}-\mathrm{OCH}_{3}\right), 13.31(\mathrm{C}-2 ") ;$ MS: $271.30\left(\mathrm{M}+\mathrm{H}^{+}\right)$. Anal. Calcd for $\mathrm{C}_{16} \mathrm{H}_{18} \mathrm{~N}_{2} \mathrm{O}_{2}$ : C, 71.09; $\mathrm{H}, 6.71 ; \mathrm{N}, 10.36$. Found: C, 70.99; $\mathrm{H}$, $6.60 ; \mathrm{N} 10.52$.

4.2.1.3. 1-(4'-Methoxyphenyl)-2-(1"-(4"'-methoxyphenyl) ethylidene) hydrazine (2c). According to the typical procedure, hydrazine 2c was obtained from acetophenone 1c as white solid (95\% yield). IR (film) $v: 3347 \mathrm{~cm}^{-1} ;{ }^{1} \mathrm{H}$ NMR (DMSO): $\delta=8.91(1 \mathrm{H}, \mathrm{s}$, $\mathrm{NH}), 7.70(2 \mathrm{H}, \mathrm{d}, J 16.8 \mathrm{~Hz}, \mathrm{H}-2$ "' and H-6"'), $7.15(2 \mathrm{H}, \mathrm{d}, J 16.8 \mathrm{~Hz}$, H-2'), 6.92 (2H, d, J $16.8 \mathrm{~Hz}, \mathrm{H}-3$ "' and H-5"'), 6.83 (2H, d, J $16.8 \mathrm{~Hz}$, H-3') $3.76\left(3 \mathrm{H}, \mathrm{s}, \mathrm{C} 4\right.$ '"- $\left.-\mathrm{OCH}_{3}\right), 3.68\left(3 \mathrm{H}, \mathrm{s}, \mathrm{C}^{\prime}\right.$ '-OCH $\left.\mathrm{OCH}_{3}\right), 2.18$ (3H, s, H$2 ") ;{ }^{13} \mathrm{C}$ NMR (DMSO): $\delta=159.4$ (C-4"'), 152.9 (C-4'), 140.9 (C-1"), 140.0 (C-1'), 132.5 (C-1'”), 126.8 (C-2"' and C-6"'), 114.8 (C-2'), 114.1 (C-3'", C-5'" and C-3'), $55.65\left(\mathrm{C}^{\prime}-\mathrm{OCH}_{3}\right), 55.54\left(\mathrm{C}^{\prime \prime} '-\mathrm{OCH}_{3}\right)$, 13.20 (C-2"); MS: $271.31\left(\mathrm{M}+\mathrm{H}^{+}\right)$. Anal. Calcd for $\mathrm{C}_{16} \mathrm{H}_{18} \mathrm{~N}_{2} \mathrm{O}_{2}$ : C, 71.09; H, 6.71; N, 10.36. Found: C, 71.19; H, 6.64; N 10.44 .

\subsubsection{Typical procedure for the synthesis of hydrazines $2 d, e$} 4.2.2.1. Synthesis of 1-(4'-methoxyphenyl)-2-(1"-(3"',4"'-dimethoxyphenyl)ethylidene) hydrazine (2d). To a stirred solution of 3',4'-dimethoxy acetophenone $(2.30 \mathrm{~g}, 12.5 \mathrm{mmol})$ in $30 \mathrm{~mL}$ of ethanol and acetic acid $(1.00 \mathrm{~mL})$, a solution of 4-methoxyphenylhydrazine hydrochloride $(3.12 \mathrm{~g}, 17.5 \mathrm{mmol})$ and $\mathrm{Et}_{3} \mathrm{~N}(2.80 \mathrm{~mL}$, $20.1 \mathrm{mmol}$ ) in $30 \mathrm{~mL}$ of ethanol was added. The reaction mixture was stirred overnight at room temperature furnishing a precipitate which was filtered off and washed with ethanol and diethylether. Hydrazine 2d was obtained as a white solid (95\% yield). IR (film) $v: 3341 \mathrm{~cm}^{-1}$; ${ }^{1} \mathrm{H}$ NMR (DMSO): $\delta=8.99(1 \mathrm{H}, \mathrm{s}, \mathrm{NH}), 7.42(1 \mathrm{H}, \mathrm{s}$, H-2"'), 7.22 (1H, d, J $8.4 \mathrm{~Hz}, \mathrm{H}-6$ '”), 7.17 (2H, d, J $8.8 \mathrm{~Hz}, \mathrm{H}-2$ '), $6.94(1 \mathrm{H}, \mathrm{d}, J 8.4 \mathrm{~Hz}, \mathrm{H}-5$ "'), $6.83(2 \mathrm{H}, \mathrm{d}, J 8.8 \mathrm{~Hz}, \mathrm{H}-3$ '), $3.81(3 \mathrm{H}$, s, C3"'- $\left.\mathrm{OCH}_{3}\right), 3.77\left(3 \mathrm{H}, \mathrm{s}, \mathrm{C} 4\right.$ '"'-OCH $\left.\mathrm{OCH}_{3}\right), 3.69\left(3 \mathrm{H}, \mathrm{s}, \mathrm{C}^{\prime}-\mathrm{OCH}_{3}\right)$, 2.21 (3H, s, H-2"); ${ }^{13} \mathrm{C}$ NMR (DMSO): $\delta=152.9$ (C-4'), 149.1 (C4"'), 149.0 (C-3"'), 140.9 (C-1"), 140.1 (C-1'), 132.8 (C-1"'), 118.3 (C-6"'), 114.8 (C-2'), 114.1 (C-3'), 111.7 (C-5"'), 108.8 (C-2"'), $55.93\left(\mathrm{C}^{\prime \prime \prime}-\mathrm{OCH}_{3}\right), 55.80\left(\mathrm{C}^{\prime \prime \prime}-\mathrm{OCH}_{3}\right), 55.66\left(\mathrm{C}^{\prime}-\mathrm{OCH}_{3}\right), 13.23$ (C-2"); MS: $301.34\left(\mathrm{M}+\mathrm{H}^{+}\right)$. Anal. Calcd for $\mathrm{C}_{17} \mathrm{H}_{20} \mathrm{~N}_{2} \mathrm{O}_{3}$ : C, 67.98; $\mathrm{H}, 6.71 ; \mathrm{N}, 9.33$. Found: C, 69.12; H, 6.60; N 9.42.

4.2.2.2. 1-(4'-Methoxyphenyl)-2-(1"-(2"',5"'-dimethoxyphenyl) ethylidene) hydrazine (2e). According to the typical procedure, hydrazine $\mathbf{2 e}$ was obtained from acetophenone $\mathbf{1 e}$ as yellowish oil (95\% yield). IR (film) $v: 3343 \mathrm{~cm}^{-1} ;{ }^{1} \mathrm{H}$ NMR (DMSO): $\delta=8.89$ $(1 \mathrm{H}, \mathrm{s}, \mathrm{NH}), 7.10(2 \mathrm{H}, \mathrm{d}, J 8.8 \mathrm{~Hz}, \mathrm{H}-2$ ') $6.96(1 \mathrm{H}, \mathrm{d}, J 8.8 \mathrm{~Hz}, \mathrm{H}-$ 3"'), 6.92 (1H, d, J $3.2 \mathrm{~Hz}, \mathrm{H}-6$ '”), 6.87 (1H, dd, J $8.8 \mathrm{HzJ} 3.2 \mathrm{~Hz}, \mathrm{H}-$ 4"'), 6.82 (2H, d, J $8.8 \mathrm{~Hz}, \mathrm{H}-3$ '), 3.75 (3H, s, C2"'-OCH $), 3.73(3 \mathrm{H}$, s, C5"'-OCH $\mathrm{OCH}_{3}, 3.68\left(3 \mathrm{H}, \mathrm{s}, \mathrm{C} 4{ }^{\prime}-\mathrm{OCH}_{3}\right), 2.16\left(3 \mathrm{H}, \mathrm{s}, \mathrm{H}-2\right.$ "); ${ }^{13} \mathrm{C}$ NMR (DMSO): $\delta=153.4$ (C-4'), 153.0 (C-5"'), 151.6 (C-2"'), 141.8 (C-1"), 140.8 (C-1'), 124.4 (C-1"'), 120.0 (C-2'), 114.8 (C-3'), 114.7 (C-4"'), 114.3 (C-6”'), 113.9 (C-3"'), $55.96\left(\mathrm{C}^{\prime}-\mathrm{OCH}_{3}\right), 55.83\left(\mathrm{C}^{\prime \prime \prime}-\mathrm{OCH}_{3}\right)$, $55.67\left(\mathrm{C}^{\prime \prime \prime}-\mathrm{OCH}_{3}\right), 17.36\left(\mathrm{C}-2\right.$ "); MS: $301.33\left(\mathrm{M}+\mathrm{H}^{+}\right)$. Anal. Calcd for $\mathrm{C}_{17} \mathrm{H}_{20} \mathrm{~N}_{2} \mathrm{O}_{3}$ : C, 67.98; $\mathrm{H}, 6.71 ; \mathrm{N}, 9.33$. Found: C, 67.84; $\mathrm{H}$, $6.77 ; \mathrm{N} 9.41$.

\subsubsection{General procedure for the synthesis of pyrazolo carboxaldehydes 3a-e}

4.2.3.1. Synthesis of 1-(4'-methoxyphenyl)-3-phenyl-1H-pyrazole-4-carbaldehyde (3a). 2,4,6-Trichloro-[1,3,5]-triazine (11 g, $60 \mathrm{mmol})$ was added to DMF $(8.3 \mathrm{~mL})$ and maintained at $25^{\circ} \mathrm{C}$. After the formation of a white solid, the reaction was monitored (TLC) until complete disappearance of TCT (20 min). Next, hydrazine $2 \mathrm{a}(3.0 \mathrm{~g}, 12 \mathrm{mmol})$ in DMF $(32 \mathrm{~mL})$ was added and the mixture was stirred for $2 \mathrm{~h}$. After completion, the reaction was cooled at $0{ }^{\circ} \mathrm{C}$ and water was added. The organic phase was extracted twice with EtOAc. The combined organic extracts were washed with saturated $\mathrm{Na}_{2} \mathrm{CO}_{3}$, brine, dried with $\mathrm{Na}_{2} \mathrm{SO}_{4}$, filtered and evaporated. The product was obtained after purification by flash column chromatography (Hex/EtOAc, 8:2) and evaporation of the solvent as white solid (60\% yield). mp $123-124{ }^{\circ} \mathrm{C}$; IR (film) $v: 1670 \mathrm{~cm}^{-1} ;{ }^{1} \mathrm{H} \mathrm{NMR}\left(\mathrm{CDCl}_{3}\right): \delta=10.0(1 \mathrm{H}, \mathrm{s}, \mathrm{CHO}), 8.46(1 \mathrm{H}, \mathrm{s}, \mathrm{H}-$ 5), 7.83 (2H, d, J $6.8 \mathrm{~Hz}, \mathrm{H}-2$ " and H-6"), 7.71 (2H, d, J $8.8 \mathrm{~Hz}, \mathrm{H}-2$ '), 7.54-7.49 (3H, m, H-3", H-4" and H-5"), 7.03 (2H, d, J 8.8 Hz, H-3'), $3.88\left(3 \mathrm{H}, \mathrm{s}, \mathrm{OCH}_{3}\right) ;{ }^{13} \mathrm{C} \mathrm{NMR}\left(\mathrm{CDCl}_{3}\right): \delta=185.2(\mathrm{CHO}), 159.3\left(\mathrm{C}-4^{\prime}\right)$, 154.6 (C-3), 132.6 (C-1'), 131.4 (C-5), 130.7 (C-1"), 129.2 (C-4"), 129.0 (C-3" and C-5"), 128.8 (C-2" and C-6"), 122.2 (C-4), 121.4 (C-2'), $114.7\left(\mathrm{C}^{\prime} 3^{\prime}\right), 55.64\left(\mathrm{OCH}_{3}\right)$; MS: $279.10\left(\mathrm{M}+\mathrm{H}^{+}\right)$. Anal. Calcd for $\mathrm{C}_{17} \mathrm{H}_{14} \mathrm{~N}_{2} \mathrm{O}_{2}$ : C, 73.37; H, 5.07; N, 10.07. Found: C, 73.20; $\mathrm{H}$, 5.14; N 9.93.

4.2.3.2. 1-(4'-Methoxyphenyl)-3-(3"-methoxyphenyl)-1H-pyrazole-4-carbaldehyde (3b). According to the general procedure, pyrazolocarboxaldehyde $\mathbf{3 b}$ was obtained from hydrazine $\mathbf{2 b}$ after purification by flash column chromatography (Hex/EtOAc, 1:1) and evaporation of the solvent as a yellow solid (55\% yield). mp 95$96{ }^{\circ} \mathrm{C}$; IR (film) v: $1676 \mathrm{~cm}^{-1}$; ${ }^{1} \mathrm{H}$ NMR $\left(\mathrm{CDCl}_{3}\right): \delta=10.0(1 \mathrm{H}, \mathrm{s}$, CHO), 8.46 (1H, s, H-5), 7.71 (2H, d, J 9.2 Hz, H-2'), 7.43-7.40 (3H, m, H-4", H-5", H-6"), 7.05 (1H, d, J $2.0 \mathrm{~Hz}, \mathrm{H}-2 "), 7.02$ (2H, d, J $\left.8.8 \mathrm{~Hz}, \mathrm{H}-3^{\prime}\right), 3.90\left(3 \mathrm{H}, \mathrm{s}, \mathrm{C} 3\right.$ "'- $\left.\mathrm{OCH}_{3}\right), 3.88\left(3 \mathrm{H}, \mathrm{s}, \mathrm{C}^{\prime}-\mathrm{OCH}_{3}\right) ;{ }^{13} \mathrm{C}$ NMR $\left(\mathrm{CDCl}_{3}\right): \delta=185.3$ (CHO), 159.8 (C-3"), 159.3 (C-4'), 154.5 (C-3), 132.6 (C-1'), 132.5 (C-1"), 130.7 (C-5), 129.8 (C-5"), 122.3 (C-4), 121.5 (C-6"), 121.4 (C-2'), 115.2 (C-4"), 114.7 (C-3'), 114.1 (C-2"), $55.64\left(\mathrm{C}^{\prime}-\mathrm{OCH}_{3}\right), 55.42\left(\mathrm{C}^{\prime \prime}-\mathrm{OCH}_{3}\right)$; MS: $309.14\left(\mathrm{M}+\mathrm{H}^{+}\right)$. Anal. Calcd for $\mathrm{C}_{18} \mathrm{H}_{16} \mathrm{~N}_{2} \mathrm{O}_{3}$ : C, 70.12; $\mathrm{H}, 5.23 ; \mathrm{N}, 9.09$. Found: C, 70.30; H, 5.14; N 9.19.

4.2.3.3. 1-(4'-Methoxyphenyl)-3-(4"-methoxyphenyl)-1H-pyrazole-4-carbaldehyde (3c). According to the general procedure, pyrazolocarboxaldehyde $\mathbf{3 c}$ was obtained from hydrazine $\mathbf{2 c}$ after purification by flash column chromatography (Hex/EtOAc, 1:1) and evaporation of the solvent as a yellow solid (55\% yield). mp 135-136 ${ }^{\circ} \mathrm{C}$; IR (film) v: $1679 \mathrm{~cm}^{-1} ;{ }^{1} \mathrm{H}$ NMR $\left(\mathrm{CDCl}_{3}\right): \delta=10.0$ $(1 \mathrm{H}, \mathrm{s}, \mathrm{CHO}), 8.43(1 \mathrm{H}, \mathrm{s}, \mathrm{H}-5), 7.80(2 \mathrm{H}, \mathrm{d}, J 8.8 \mathrm{~Hz}, \mathrm{H}-2$ " and $\mathrm{H}-$ 6"), $7.70(2 \mathrm{H}, \mathrm{d}, J 8.8 \mathrm{~Hz}, \mathrm{H}-2$ '), $7.17(2 \mathrm{H}, \mathrm{d}, J 8.8 \mathrm{~Hz}, \mathrm{H}-3$ " and $\mathrm{H}-$ 5”), 7.02 (2H, d, J $8.8 \mathrm{~Hz}, \mathrm{H}-3$ '), 3.89 (3H, s, C4"-OCH $), 3.87(3 \mathrm{H}$, $\left.\mathrm{s}, \mathrm{C}^{\prime}-\mathrm{OCH}_{3}\right) ;{ }^{13} \mathrm{C} \mathrm{NMR}\left(\mathrm{CDCl}_{3}\right): \delta=185.2(\mathrm{CHO}), 160.4$ (C-4"), 159.2 (C-4'), 154.3 (C-3), 132.6 (C-1'), 131.0 (C-5), 130.2 (C-2" and C-6"), 123.9 (C-1"), 122.0 (C-4), 121.3 (C-2'), 114.7 (C-3" and C-5"), 114.2 (C-3'), $55.64\left(\mathrm{C}^{\prime}-\mathrm{OCH}_{3}\right), 55.40\left(\mathrm{C}-4 "-\mathrm{OCH}_{3}\right)$; MS: 
309.13 $\left(\mathrm{M}+\mathrm{H}^{+}\right)$. Anal. Calcd for $\mathrm{C}_{18} \mathrm{H}_{16} \mathrm{~N}_{2} \mathrm{O}_{3}$ : C, 70.12; $\mathrm{H}, 5.23 ; \mathrm{N}$, 9.09. Found: C, 69.98; H, 5.16; N 9.19.

4.2.3.4. 1-(4'-Methoxyphenyl)-3-(3",4"-dimethoxyphenyl)-1Hpyrazole-4-carbaldehyde (3d). According to the general procedure, pyrazolocarboxaldehyde $\mathbf{3 d}$ was obtained from hydrazine 2d after purification by flash column chromatography (Hex/EtOAc, $1: 1$ ) and evaporation of the solvent as a yellow solid (50\% yield). mp 113-114 ${ }^{\circ} \mathrm{C}$; IR (film) $v$ : $1686 \mathrm{~cm}^{-1} ;{ }^{1} \mathrm{H}$ NMR (DMSO): $\delta=9.95$ (1H, s, CHO), 9.16 (1H, s, H-5), 7.88 (2H, d, J 8.8 Hz, H-2'), 7.54 (1H, s, H-2"), 7.51 ( $1 \mathrm{H}, \mathrm{d}, J 8.4 \mathrm{~Hz}, \mathrm{H}-6$ "), 7.10 (2H, d, $J$ $8.8 \mathrm{~Hz}, \mathrm{H}-3$ '), 7.06 (1H, d, J $8.4 \mathrm{~Hz}, \mathrm{H}-5$ ") $3.83\left(3 \mathrm{H}, \mathrm{s}, \mathrm{C} 3\right.$ "- $\left.-\mathrm{OCH}_{3}\right)$, $3.81\left(6 \mathrm{H}, \mathrm{s}, \mathrm{C}^{\prime}-\mathrm{OCH}_{3}\right.$ and $\left.\mathrm{C}^{\prime \prime}-\mathrm{OCH}_{3}\right) ;{ }^{13} \mathrm{C}$ NMR (DMSO): $\delta=185.1$ (CHO), 159.0 (C-4'), 152.9 (C-3), 150.1 (C-4"), 149.0 (C3"), 134.9 (C-1'), 132.6 (C-5), 124.3 (C-1"), 122.2 (C-4), 121.9 (C6"), 121.3 (C-2'), 115.2 (C-3'), 112.4 (C-2"), 112.0 (C-5"), 55.98 $\left(\mathrm{C}^{\prime \prime}-\mathrm{OCH}_{3}, \mathrm{C}^{\prime \prime}-\mathrm{OCH}_{3}\right.$ and $\left.\mathrm{C}^{\prime}-\mathrm{OCH}_{3}\right)$; MS: $339.12\left(\mathrm{M}+\mathrm{H}^{+}\right)$. Anal. Calcd for $\mathrm{C}_{19} \mathrm{H}_{18} \mathrm{~N}_{2} \mathrm{O}_{4}$ : C, 67.44; $\mathrm{H}, 5.36$;, 8.28. Found: C, 67.64; $\mathrm{H}, 5.23 ; \mathrm{N}, 8.19$.

4.2.3.5. 1-(4'-Methoxyphenyl)-3-(2",5"-dimethoxyphenyl)-1Hpyrazole-4-carbaldehyde (3e). According to the general procedure, pyrazolocarboxaldehyde $\mathbf{3 e}$ was obtained from hydrazine 2e after purification by flash column chromatography (Hex/EtOAc, $1: 1$ ) and evaporation of the solvent as a yellow solid (50\% yield). mp 120-121 ${ }^{\circ} \mathrm{C}$; IR (film) $v: 1688 \mathrm{~cm}^{-1} ;{ }^{1} \mathrm{H} \mathrm{NMR}\left(\mathrm{CDCl}_{3}\right): \delta=9.79$ (1H, s, CHO), 8.42 (1H, s, H-5), 7.69 (2H, d, J $8.8 \mathrm{~Hz}, \mathrm{H}-2$ '), 7.19 (1H, d, J $\left.3.2 \mathrm{~Hz}, \mathrm{H}-6^{\prime \prime}\right), 7.01$ (2H, d, J $8.8 \mathrm{~Hz}, \mathrm{H}-3$ '), 6.99 (2H, d, J $6.8 \mathrm{~Hz}, \mathrm{H}-3$ " and $\mathrm{H}-4$ "), 3.87 (3H, s, C2"- $\left.\mathrm{OCH}_{3}\right), 3.84(3 \mathrm{H}, \mathrm{s}, \mathrm{C} 5$ "$\left.\mathrm{OCH}_{3}\right), 3.79\left(3 \mathrm{H}, \mathrm{s}, \mathrm{C}^{\prime}-\mathrm{OCH}_{3}\right) ;{ }^{13} \mathrm{C} \mathrm{NMR}\left(\mathrm{CDCl}_{3}\right): \delta=185.0(\mathrm{CHO})$, 159.2 (C-4'), 153.8 (C-3), 151.6 (C-5”), 151.0 (C-2”), 132.6 (C-1'), 130.7 (C-5), 123.2 (C-1"), 122.7 (C-4), 121.1(C-2'), 117.7 (C-6"), 114.1 (C-3'), 113.0 (C-3"), 110.8 (C-4"), $57.52\left(\mathrm{C}^{\prime}-\mathrm{OCH}_{3}\right), 57.27$ $\left(\mathrm{C}^{\prime \prime}-\mathrm{OCH}_{3}\right), 57.02\left(\mathrm{C} 2 "-\mathrm{OCH}_{3}\right)$; MS: $339.15\left(\mathrm{M}+\mathrm{H}^{+}\right)$. Anal. Calcd for $\mathrm{C}_{19} \mathrm{H}_{18} \mathrm{~N}_{2} \mathrm{O}_{4}$ : C, 67.44; $\mathrm{H}, 5.36 ; \mathrm{N}, 8.28$. Found: C, 67.29; $\mathrm{H}$, 5.19; N, 8.16.

\subsubsection{General procedure for the demethylation of pyrazolo carboxaldehydes 3a-e}

4.2.4.1. Synthesis of 1-(4'-hydroxyphenyl)-3-phenyl-1H-pyrazole-4-carboxaldehyde (4a). To a stirred solution of the protected pyrazolocarboxaldehyde $3 \mathbf{a}(0.20 \mathrm{~g}, 0.72 \mathrm{mmol})$ in $\mathrm{CH}_{2} \mathrm{Cl}_{2}$ $\left(22 \mathrm{~mL}\right.$ ) at $-78{ }^{\circ} \mathrm{C} \mathrm{BBr}_{3}$ (3.6 mmol, $1.0 \mathrm{M}$ in $\mathrm{CH}_{2} \mathrm{Cl}_{2}, 5$ equiv per bond, $3.6 \mathrm{~mL}$ ) dropwise was added. The reaction was kept at $-78^{\circ} \mathrm{C}$ for $1 \mathrm{~h}$ and then for $16 \mathrm{~h}$ at room temperature. The solution was cooled at $0{ }^{\circ} \mathrm{C}$, neutralized with $\mathrm{MeOH}$ and then $\mathrm{HCl} 1 \mathrm{~N}$ was added. The organic phase was extracted twice with EtOAc. The combined organic extracts were washed with water, brine, dried with $\mathrm{Na}_{2} \mathrm{SO}_{4}$, filtered and evaporated. The product was obtained after flash column chromatography (Hex/EtOAc 1:1) and evaporation of the solvent as brown solid (95\% yield). Mp 162-163 ${ }^{\circ} \mathrm{C}$; IR (film) $v$ : $3415,1658 \mathrm{~cm}^{-1}$; ${ }^{1} \mathrm{H}$ NMR (DMSO): $\delta=9.93(1 \mathrm{H}, \mathrm{s}$, CHO), 9.13 (1H, s, H-5), 7.88 (2H, d, J $8.0 \mathrm{~Hz}, \mathrm{H}-2$ " and H-6"), 7.75 ( $\left.2 \mathrm{H}, \mathrm{d}, J 8.8 \mathrm{~Hz}, \mathrm{H}-2^{\prime}\right), 7.47$ (3H, m, H-3", H-4" and H-5"), 6.91 (2H, d, J 8.8 Hz, H-3'); ${ }^{13} \mathrm{C}$ NMR (DMSO): $\delta=185.0$ (CHO), 157.5 (C-4'), 152.7 (C-3), 134.6 (C-1'), 131.8 (C-5), 131.3 (C-1"), 129.5 (C-4"), 129.1 (C-3" and C-5"), 129.0 (C-2" and C-6"), 122.1 (C-4), 121.5 (C-2'), 116.4 (C-3'); MS: $265.05\left(\mathrm{M}+\mathrm{H}^{+}\right)$. Anal. Calcd for $\mathrm{C}_{16} \mathrm{H}_{12} \mathrm{~N}_{2} \mathrm{O}_{2}$ : C, 72.72; H, 4.58; N, 10.60. Found: C, 72.94; H, 4.47; $\mathrm{N}, 10.74$.

4.2.4.2. 1-(4'-Hydroxyphenyl)-3-(3"-hydroxyphenyl)-1H-pyrazole4-carboxaldehyde (4b). According to the general procedure, demethylated pyrazolocarboxaldehyde $\mathbf{4 b}$ was obtained from pyrazolocarboxaldehyde $\mathbf{3 b}$ after purification by flash column chromatography (Hex/EtOAc 1:1) and evaporation of the solvent as a yellow solid (95\% yield). Mp $224-225^{\circ} \mathrm{C}$; IR (film) $v$ : 3388 , $1662 \mathrm{~cm}^{-1}$; ${ }^{1} \mathrm{H}$ NMR (DMSO): $\delta=9.96(1 \mathrm{H}, \mathrm{s}, \mathrm{CHO}), 9.88(1 \mathrm{H}, \mathrm{br}$. s, OH), $9.64(1 \mathrm{H}$, br s, OH), $9.09(1 \mathrm{H}, \mathrm{s}, \mathrm{H}-5), 7.76(2 \mathrm{H}, \mathrm{d}, J 8.8 \mathrm{~Hz}$, H-2'), 7.31 (3H, m, H-2", H-4" and H-6"), 6.92 (2H, d, J $8.8 \mathrm{~Hz}, \mathrm{H}-$ 3'), 6.88 (1H, ddd, J $7.2 \mathrm{HzJ} 2.4 \mathrm{~Hz}, \mathrm{H}-5 ") ;{ }^{13} \mathrm{C}$ NMR (DMSO): $\delta=185.1$ (CHO), 157.9 (C-3"), 157.5 (C-4'), 153.0 (C-3), 134.0 (C1'), 133.0 (C-5), 131.3 (C-5"), 130.1 (C-1"), 122.1 (C-4), 121.5 (C2'), 120.0 (C-2"), 116.6 (C-4"), 116.4 (C-3'), 115.8 (C-6"); MS: $281.06\left(\mathrm{M}+\mathrm{H}^{+}\right)$. Anal. Calcd for $\mathrm{C}_{16} \mathrm{H}_{12} \mathrm{~N}_{2} \mathrm{O}_{3}$ : C, 68.56; $\mathrm{H}, 4.32 ; \mathrm{N}$, 9.99. Found: C, 68.74; H, 4.46; N, 10.20 .

4.2.4.3. 1-(4'-Hydroxyphenyl)-3-(4"-hydroxyphenyl)-1H-pyrazole4-carboxaldehyde (4c). According to the general procedure, demethylated pyrazolocarboxaldehyde $4 \mathbf{c}$ was obtained from pyrazolocarboxaldehyde $\mathbf{3 c}$ after purification by flash column chromatography (Hex/EtOAc 1:1) and evaporation of the solvent as a light brown solid (95\% yield). mp $216-217^{\circ} \mathrm{C}$; IR (film) $v$ : 3320 , $1650 \mathrm{~cm}^{-1}$; ${ }^{1} \mathrm{H}$ NMR (DMSO): $\delta=9.91(1 \mathrm{H}, \mathrm{s}, \mathrm{CHO}), 9.82$ (2H, br. s, $\mathrm{OH}), 9.04$ (1H, s, H-5), 7.74 (4H, d, J 6.8 Hz, H-2", H-6" and H-2'), 6.89 (2H, d, J 9.2 Hz, H-3" and H-5") 6.87 (2H, d, J 9.2 Hz, H-3'); ${ }^{13} \mathrm{C}$ NMR (DMSO): $\delta=185.0$ (CHO), 158.8 (C-4"), 157.4 (C-4'), 153.0 (C-3), 134.2 (C-1'), 131.4 (C-5), 130.5 (C-2" and C-6"), 122.6 (C-1"), 121.8 (C-4), 121.4 (C-2'), 116.3 (C-3" and C-5"), 115.8 (C-3'); MS: $281.06\left(\mathrm{M}+\mathrm{H}^{+}\right)$. Anal. Calcd for $\mathrm{C}_{16} \mathrm{H}_{12} \mathrm{~N}_{2} \mathrm{O}_{3}$ : C, 68.56; H, 4.32; N, 9.99. Found: C, 68.41; H, 4.40; N, 10.12 .

4.2.4.4. 1-(4'-Hydroxyphenyl)-3-(3",4"-dihydroxyphenyl)-1H-pyrazole-4-carboxaldehyde (4d). According to the general procedure, demethylated pyrazolocarboxaldehyde $4 \mathbf{d}$ was obtained from pyrazolocarboxaldehyde 3d after purification by flash column chromatography (Hex/EtOAc 7:3) and evaporation of the solvent as foam (90\% yield). IR (film) $v: 3438,1641 \mathrm{~cm}^{-1} ;{ }^{1} \mathrm{H}$ NMR (DMSO): $\delta=9.94(1 \mathrm{H}, \mathrm{s}, \mathrm{CHO}), 9.85(1 \mathrm{H}, \mathrm{s}, \mathrm{OH}), 9.28(1 \mathrm{H}, \mathrm{s}, \mathrm{OH}), 9.18(1 \mathrm{H}$, s, OH), $9.03(1 \mathrm{H}, \mathrm{s}, \mathrm{H}-5), 7.75(2 \mathrm{H}, \mathrm{d}, J 9.2 \mathrm{~Hz}, \mathrm{H}-2$ '), $7.33(1 \mathrm{H}, \mathrm{d}, J$ $2.0 \mathrm{~Hz}, \mathrm{H}-2$ "), 7.23 (1H, dd, J $8.0 \mathrm{~J} 2.0 \mathrm{~Hz}, \mathrm{H}-6$ "), 6.92 (2H, d, J 8.8, H-3'), 6.85 (1H, d, J $\left.8.0 \mathrm{~Hz}, \mathrm{H}-5^{\prime \prime}\right) ;{ }^{13} \mathrm{C}$ NMR (DMSO): $\delta=185.6$ (CHO), 157.0 (C-4'), 153.3 (C-3), 146.6 (C-4"), 145.2 (C-3"), 134.3 (C-1'), 131.4 (C-5), 123.0 (C-1"), 121.6 (C-2' and C-4), 121.0 (C2"), 116.4 (C-3'), 116.2 (C-5"), 116.0 (C-6"); MS: $297.06\left(\mathrm{M}+\mathrm{H}^{+}\right)$. Anal. Calcd for $\mathrm{C}_{16} \mathrm{H}_{12} \mathrm{~N}_{2} \mathrm{O}_{4}$ : C, 64.86; $\mathrm{H}, 4.08$; N, 9.46. Found: $\mathrm{C}$, 64.78; $\mathrm{H}, 4.01 ; \mathrm{N}, 9.38$.

4.2.4.5. 1-(4'-Hydroxyphenyl)-3-(2",5"-dihydroxyphenyl)-1H-pyrazole-4-carboxaldehyde (4e). According to the general procedure, demethylated pyrazolocarboxaldehyde $4 \mathbf{e}$ was obtained from pyrazolocarboxaldehyde $\mathbf{3 e}$ after purification by flash column chromatography (Hex/EtOAc 1:1) and evaporation of the solvent as a brown solid (90\% yield). mp 208-209 ${ }^{\circ} \mathrm{C}$; IR (film) $v$ : 3289, $1669 \mathrm{~cm}^{-1}$; ${ }^{1} \mathrm{H}$ NMR (DMSO): $\delta=9.84(1 \mathrm{H}$, br. s, OH), $9.78(1 \mathrm{H}, \mathrm{s}$, CHO), $9.22(1 \mathrm{H}$, br. s, OH), $8.94(2 \mathrm{H}, \mathrm{s}, \mathrm{H}-5$ and $\mathrm{OH}), 7.75(2 \mathrm{H}, \mathrm{d}, J$ $8.4 \mathrm{~Hz}, \mathrm{H}-2$ '), 6.94 (1H, d, J $2.4 \mathrm{~Hz}, \mathrm{H}-6$ "), 6.56 (2H, d, J $8.8 \mathrm{~Hz}, \mathrm{H}-$ 3'), 6.82 (1H, d, J 8.4, H-3"), 6.74 (1H, d, J $8.0 \mathrm{~Hz}, \mathrm{H}-4 ") ;{ }^{13} \mathrm{C}$ NMR (DMSO): $\delta=184.2$ (CHO), 157.4 (C-4') 151.9 (C-3), 150.4 (C-5”), 147.8 (C-2"), 131.5 (C-1'), 130.4 (C-5), 122.7 (C-1"), 121.4 (C-2'), 119.2 (C-4), 117.7 (C-3"), 117.3 (C-4"), 117.1 (C-6"), 116.3 (C-3'); MS: $297.02\left(\mathrm{M}+\mathrm{H}^{+}\right)$. Anal. Calcd for $\mathrm{C}_{16} \mathrm{H}_{12} \mathrm{~N}_{2} \mathrm{O}_{4}: \mathrm{C}, 64.86 ; \mathrm{H}$, 4.08; N, 9.46. Found: C, 64.72; H, 3.99; N 9.35.

\subsubsection{General procedure for the synthesis of carboxylic acids 5a-e}

4.2.5.1. Synthesis of 1-(4'-Methoxy-phenyl)-3-phenyl-1H-pyrazole-4-carboxylic acid (5a). To a cooled $\left(0^{\circ} \mathrm{C}\right)$ solution of pyrazolocarboxaldehyde $3 a(0.40 \mathrm{~g}, 1.4 \mathrm{mmol})$ in acetone $(19 \mathrm{~mL})$ a cold solution $\left(0{ }^{\circ} \mathrm{C}\right)$ of $\mathrm{NaClO}_{2}(0.38 \mathrm{~g}, 3.4 \mathrm{mmol})$ and $\mathrm{H}_{2} \mathrm{NSO}_{3} \mathrm{H}(0.38 \mathrm{~g}$, $3.9 \mathrm{mmol})$ in water $(19 \mathrm{~mL})$ was added. The subsequent mixture is stirred for $30 \mathrm{~min}$, until total consumption of the starting mate- 
rial. The solution was extracted twice with EtOAc and the combined organic extracts were washed twice with an aqueous solution of $10 \% \mathrm{Na}_{2} \mathrm{~S}_{2} \mathrm{O}_{3}$, water and brine. The organic layer was dried with $\mathrm{Na}_{2} \mathrm{SO}_{4}$, filtered and evaporated, to provide carboxylic acid $\mathbf{5 a}$ as white solid (95\% yield). Mp 203-204 ${ }^{\circ} \mathrm{C}$; IR (film) $v$ : $1697 \mathrm{~cm}^{-1}$; ${ }^{1} \mathrm{H}$ NMR (DMSO): $\delta=12.6(1 \mathrm{H}, \mathrm{br} . \mathrm{s}, \mathrm{COOH}), 8.97(1 \mathrm{H}$, s, H-5), 7.89 (2H, d, J 9.2 Hz, H-2'), 7.84 (2H, d, J 7.6 Hz, H-2" and H-6"), 7.46-7.42 (3H, m, H-3", H-4" and H-5"), 7.08 (2H, d, J $\left.9.2 \mathrm{~Hz}, \mathrm{H}-3^{\prime}\right), 3.82\left(3 \mathrm{H}, \mathrm{s}, \mathrm{OCH}_{3}\right) ;{ }^{13} \mathrm{C}$ NMR (DMSO): $\delta=164.3$ (COOH), 158.8 (C-4'), 152.9 (C-3), 133.8 (C-1'), 132.8 (C-5), 132.7 (C-1"), 129.6 (C-3" and C-5"), 128.8 (C-4"), 128.2 (C-2" and C-6"), 121.1 (C-2'), 115.1 (C-3'), 113.9 (C-4), $55.94\left(\mathrm{OCH}_{3}\right)$; MS: 295.21 $\left(\mathrm{M}+\mathrm{H}^{+}\right)$. Anal. Calcd for $\mathrm{C}_{17} \mathrm{H}_{14} \mathrm{~N}_{2} \mathrm{O}_{3}$ : C, 69.38; H, 4.79; N, 9.52. Found: C, 69.62; H, 4.89; N, 9.40.

4.2.5.2. 1-(4'-Methoxyphenyl)-3-(3"-mehoxyphenyl)-1H-pyrazole-4-carboxylic acid (5b). According to the general procedure, carboxylic acid $\mathbf{5 b}$ was obtained from pyrazolocarboxaldehyde $\mathbf{3 b}$ as white solid (95\% yield). mp $217-218{ }^{\circ} \mathrm{C}$; IR (film) $v: 1696 \mathrm{~cm}^{-1}$; ${ }^{1} \mathrm{H}$ NMR (DMSO): $\delta=12.5$ (1H, br. s, COOH), 8.96 (1H, s, H-5), 7.89 $(2 \mathrm{H}, \mathrm{d}, J 8.8 \mathrm{~Hz}, \mathrm{H}-2$ '), 7.45-7.42 (2H, m, H-2" and H-6"), $7.36(1 \mathrm{H}$, t, J $\left.8.0 \mathrm{~Hz}, \mathrm{H}-5^{\prime}\right), 7.09$ (2H, d, J $\left.8.8 \mathrm{~Hz}, \mathrm{H}-3^{\prime}\right), 7.00(1 \mathrm{H}, \mathrm{d}, J 8.8 \mathrm{~Hz}$, $\mathrm{H}-4$ ") $3.82\left(3 \mathrm{H}, \mathrm{s}, \mathrm{C} 3\right.$ "- $\left.\mathrm{OCH}_{3}\right), 3.81\left(3 \mathrm{H}, \mathrm{s}, \mathrm{C}^{\prime}-\mathrm{OCH}_{3}\right) ;{ }^{13} \mathrm{C} \mathrm{NMR}$ (DMSO): $\delta=164.3(\mathrm{COOH}), 159.1\left(\mathrm{C}-3^{\prime \prime}\right), 158.8\left(\mathrm{C}-4^{\prime}\right), 152.6(\mathrm{C}-3)$, 133.9 (C-1'), 133.8 (C-5), 132.8 (C-1"), 129.3 (C-5"), 121.8 (C-6"), 121.1 (C-2'), 115.2 (C-4"), 115.1 (C-3'), 114.4 (C-2"), 113.9 (C-4) $55.93\left(\mathrm{C}^{\prime}-\mathrm{OCH}_{3}\right), 55.51\left(\mathrm{C}^{\prime \prime}-\mathrm{OCH}_{3}\right)$; $\mathrm{MS}$ : $325.11\left(\mathrm{M}+\mathrm{H}^{+}\right)$. Anal. Calcd for $\mathrm{C}_{18} \mathrm{H}_{16} \mathrm{~N}_{2} \mathrm{O}_{4}$ : C, 66.66; $\mathrm{H}, 4.97 ; \mathrm{N}, 8.64$. Found: $\mathrm{C}, 66.82$; $\mathrm{H}, 4.89 ; \mathrm{N}, 8.75$.

4.2.5.3. 1-(4'-Methoxyphenyl)-3-(4"-mehoxyphenyl)-1H-pyrazole-4-carboxylic acid (5c). According to the general procedure, carboxylic acid $\mathbf{5 c}$ was obtained from pyrazolocarboxaldehyde $\mathbf{3 c}$ as white solid (95\% yield). $\mathrm{mp} 236-237{ }^{\circ} \mathrm{C}$; IR (film) $v: 1691 \mathrm{~cm}^{-1}$; ${ }^{1} \mathrm{H}$ NMR (DMSO): $\delta=12.5$ (1H, br. s, COOH), 8.93 (1H, s, H-5), 7.85 (2H, d, J $8.4 \mathrm{~Hz}, \mathrm{H}-2$ " and H-6"), $7.82(2 \mathrm{H}, \mathrm{d}, J 8.4 \mathrm{~Hz}, \mathrm{H}-2$ '), 7.08 ( $2 \mathrm{H}, \mathrm{d}, J 8.4 \mathrm{~Hz}, \mathrm{H}-3$ " and H-5"), 7.01 (2H, d, J $\left.8.4 \mathrm{~Hz}, \mathrm{H}-3^{\prime}\right), 3.82$ $\left(6 \mathrm{H}, \mathrm{s}, \mathrm{OCH}_{3}\right) ;{ }^{13} \mathrm{C}$ NMR (DMSO): $\delta=164.4(\mathrm{COOH}), 159.9$ (C-4"), 158.7 (C-4'), 152.7 (C-3), 133.7 (C-1'), 132.8 (C-5), 130.8 (C-2" and C-6"), 125.0 (C-1"), 121.0 (C-2'), 115.0 (C-3" and C-5"), 113.7 (C-3'), 113.4 (C-4), $55.92\left(\mathrm{C}^{\prime}-\mathrm{OCH}_{3}\right), 55.60\left(\mathrm{C}^{\prime \prime}-\mathrm{OCH}_{3}\right)$; MS: $325.11\left(\mathrm{M}+\mathrm{H}^{+}\right)$. Anal. Calcd for $\mathrm{C}_{18} \mathrm{H}_{16} \mathrm{~N}_{2} \mathrm{O}_{4}$ : C, 66.66; $\mathrm{H}, 4.97 ; \mathrm{N}$, 8.64. Found: C, 66.78; $\mathrm{H}, 4.88$; N, 8.56.

4.2.5.4. 1-(4'-Methoxyphenyl)-3-(3",4"'-dimethoyphenyl)-1Hpyrazole-4-carboxylic acid (5d). According to the general procedure, carboxylic acid 5d was obtained from pyrazolocarboxaldehyde $3 \mathrm{~d}$ as white solid (95\% yield). mp $172-173^{\circ} \mathrm{C}$; IR (film) $v$ : $1697 \mathrm{~cm}^{-1} ;{ }^{1} \mathrm{H}$ NMR (acetone-d6): $\delta=8.76(1 \mathrm{H}, \mathrm{s}, \mathrm{H}-5), 7.91(2 \mathrm{H}$, d, $J 8.8 \mathrm{~Hz}, \mathrm{H}-2$ '), $7.71(1 \mathrm{H}, \mathrm{d}, J 2.0 \mathrm{~Hz}, \mathrm{H}-2$ "), $7.62(1 \mathrm{H}$, dd, $J$ $8.4 \mathrm{HzJ} 2.0 \mathrm{~Hz}, \mathrm{H}-6$ "), 7.11 (2H, d, $J 8.8 \mathrm{~Hz}, \mathrm{H}-3$ '), 7.01 (1H, d, $J$ $8.4 \mathrm{~Hz}, \mathrm{H}-5$ ") 3.88 (3H, s, C3"'-OCH $), 3.87$ (3H, s, C4"-OCH $), 3.86$ $\left(3 \mathrm{H}, \mathrm{s}, \mathrm{C}^{\prime}-\mathrm{OCH}_{3}\right) ;{ }^{13} \mathrm{C}$ NMR (acetone d6): $\delta=165.4(\mathrm{COOH}), 159.3$ (C-4'), 152.4 (C-3"), 151.9 (C-4"), 144.6 (C-3), 133.1 (C-1'), 133.0 (C-5), 121.9 (C-6"), 120.7 (C-1" and C-2'), 114.5 (C-3'), 113.4 (C4), 111.0 (C-5"), 110.0 (C-2"), $55.18\left(\mathrm{OCH}_{3}\right)$; MS: $355.14\left(\mathrm{M}+\mathrm{H}^{+}\right)$. Anal. Calcd for $\mathrm{C}_{19} \mathrm{H}_{18} \mathrm{~N}_{2} \mathrm{O}_{5}: \mathrm{C}, 64.40 ; \mathrm{H}, 5.12 ; \mathrm{N}, 7.91$. Found: $\mathrm{C}$, 64.62; H, 4.99; N 7.79.

4.2.5.5. 1-(4'-Methoxyphenyl)-3-(2",5"-dimethoyphenyl)-1H-pyrazole-4-carboxylic acid (5e). According to the general procedure, carboxylic acid 5e was obtained from pyrazolocarboxaldehyde 3e as white solid (95\% yield). $\mathrm{mp} 221-222^{\circ} \mathrm{C}$; I.R. (film) $v: 1696 \mathrm{~cm}^{-1}$; ${ }^{1} \mathrm{H}$ NMR (DMSO): $\delta=8.86$ (1H, s, H-5), 7.84 (2H, d, J $8.8 \mathrm{~Hz}, \mathrm{H}-2$ '), 7.07 (2H, d, J 8.8 Hz, H-3'), 7.00 (1H, d, J 8.8 Hz, H-3"), 6.96 (1H, dd, J $8.8 \mathrm{HzJ} 2.8 \mathrm{~Hz}, \mathrm{H}-4$ "), 6.91 (1H, d, J $2.8 \mathrm{~Hz}, \mathrm{H}-6$ "), 3.81 (3H, s,
$\left.\mathrm{C}^{\prime \prime}-\mathrm{OCH}_{3}\right), 3.74\left(3 \mathrm{H}, \mathrm{s}, \mathrm{C} 5\right.$ "- $\left.-\mathrm{OCH}_{3}\right), 3.66\left(3 \mathrm{H}, \mathrm{s}, \mathrm{C}^{\prime}\right.$ '-OCH $\left.\mathrm{OCH}_{3}\right) ;{ }^{13} \mathrm{C} \mathrm{NMR}$ (DMSO): $\delta=164.1$ (COOH), 158.6 (C-4'), 153.1 (C-5"), 152.1 (C-2"), 150.4 (C-3), 133.0 (C-5), 131.8 (C-1'), 123.5 (C-4), 120.9 (C-2'), 116.5 (C-1") 115.1 (C-3' and C-4") 114.9 (C-3"), 112.8 (C-6"), 56.29 (C4'-OCH3), 55.96 (C5"-OCH3) 55.94 (C2"-OCH3); MS: 355.14 $\left(\mathrm{M}+\mathrm{H}^{+}\right)$. Anal. Calcd for $\mathrm{C}_{19} \mathrm{H}_{18} \mathrm{~N}_{2} \mathrm{O}_{5}: \mathrm{C}, 64.40 ; \mathrm{H}, 5.12 ; \mathrm{N}, 7.91$. Found: C, 64.57; H, 5.02; N 7.81.

\subsubsection{General procedure for the synthesis of amides 6a-e} 4.2.6.1. Synthesis of $\mathbf{N}$-methoxy-1-(4'-methoxyphenyl)-3-phenyl-1H-pyrazole-4-carboxamide (6a). $\mathrm{Et}_{3} \mathrm{~N}(0.17 \mathrm{~mL}, 1.2 \mathrm{mmol})$, was added dropwise into a solution of carboxylic acid $5 \mathbf{a}(0.17 \mathrm{~g}$, $0.58 \mathrm{mmol})$ and $\mathrm{NH}_{2} \mathrm{OMe} \cdot \mathrm{HCl}(0.074 \mathrm{~g}, 0.87 \mathrm{mmol})$ in $\mathrm{MeCN}$ $(7.0 \mathrm{~mL})$. After stirring the mixture at room temperature for $30 \mathrm{~min}$, TBTU $(0.28 \mathrm{~g}, 0.87 \mathrm{mmol})$ was added and the stirring was continued for $30 \mathrm{~min}$ until total consumption of the starting material. Then brine was added and the solution was extracted twice with EtOAc. The combined organic extracts were washed with $\mathrm{HCl} 1 \mathrm{~N}$, water, $5 \%$ aq $\mathrm{NaHCO}_{3}$ and brine. The organic layer was dried with $\mathrm{Na}_{2} \mathrm{SO}_{4}$, filtered and evaporated. After drying in vacuum over $\mathrm{P}_{2} \mathrm{O}_{5}$ carboxamide $6 \mathbf{a}$ was obtained as white solid (95\% yield). mp 157-158 ${ }^{\circ} \mathrm{C}$; IR (film) $v$ : $1664 \mathrm{~cm}^{-1} ;{ }^{1} \mathrm{H}$ NMR (DMSO): $\delta=11.4$ $(1 \mathrm{H}, \mathrm{s}, \mathrm{NH}) 8.75$ (1H, s, H-5), $7.84-7.80$ (4H, m, H-2', H-2" and $\mathrm{H}-$ 6"), 7.47-7.38 (3H, m, H-3", H-4" and H-5"), 7.11 (2H, d, J 9.2 Hz, H$\left.3^{\prime}\right), 3.82\left(3 \mathrm{H}, \mathrm{s}, \mathrm{NH}-\mathrm{OCH}_{3}\right), 3.71\left(3 \mathrm{H}, \mathrm{s}, \mathrm{C} 4^{\prime}-\mathrm{OCH}_{3}\right) ;{ }^{13} \mathrm{C}$ NMR (DMSO): $\delta=161.2(\mathrm{CONH}), 158.6$ (C-4'), 150.9 (C-3), 133.0 (C-1'), 132.6 (C-1"), 130.2 (C-5), 128.7 (C-4"), 128.6 (C-3" and C-5"), 128.4 (C-2" and C-6"), 120.8 (C-2'), 115.2 (C-3'), 114.6 (C-4), $63.41\left(\mathrm{NH}-\mathrm{OCH}_{3}\right), 55.96\left(\mathrm{C}^{\prime}-\mathrm{OCH}_{3}\right)$; MS: $324.13\left(\mathrm{M}+\mathrm{H}^{+}\right)$. Anal. Calcd for $\mathrm{C}_{18} \mathrm{H}_{17} \mathrm{~N}_{3} \mathrm{O}_{3}$ : C, 66.86; $\mathrm{H}, 5.30 ; \mathrm{N}, 13.00$. Found: C, 66.73; H, 5.22; N 13.13 .

4.2.6.2. N-Methoxy-1-(4'-methoxyphenyl)-3-(3"'-methoxyphenyl)1H-pyrazole-4-carboxamide (6b). According to the general procedure, carboxamide $\mathbf{6 b}$ was obtained from carboxylic acid $\mathbf{5 b}$ as white solid (90\% yield). mp $176-177^{\circ} \mathrm{C}$; IR (film) $v: 1643 \mathrm{~cm}^{-1}$; ${ }^{1} \mathrm{H}$ NMR (DMSO): $\delta=11.5(1 \mathrm{H}, \mathrm{s}, \mathrm{NH}), 8.74(1 \mathrm{H}, \mathrm{s}, \mathrm{H}-5), 7.82(2 \mathrm{H}$, d, $J$ 7.6 Hz, H-2'), 7.45-7.42 (2H, m, H-2" and H-6"), $7.37(1 \mathrm{H}, \mathrm{t}, J$ $7.2 \mathrm{~Hz}, \mathrm{H}-5$ "), 7.12 (2H, d, J 7.6 Hz, H-3'), 6.99 (1H, d, J $6.4 \mathrm{~Hz}, \mathrm{H}-$ 4"), $3.82\left(3 \mathrm{H}, \mathrm{s}, \mathrm{NH}-\mathrm{OCH}_{3}\right), 3.81\left(3 \mathrm{H}, \mathrm{s}, \mathrm{C}^{\prime}\right.$ "- $\left.\mathrm{OCH}_{3}\right), 3.72(3 \mathrm{H}, \mathrm{s}$, $\left.\mathrm{C}^{\prime}-\mathrm{OCH}_{3}\right) ;{ }^{13} \mathrm{C}$ NMR (DMSO): $\delta=161.4(\mathrm{CONH}), 159.5$ (C-3"), 158.7 (C-4'), 150.5 (C-3), 133.9 (C-1'), 133.0 (C-5), 130.3 (C-1"), 129.8 (C-5”), 120.8 (C-2'), 120.6 (C-6”), 115.2 (C-3'), 114.7 (C-4),

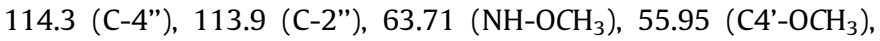
$55.93\left(\mathrm{C} 3 "^{\prime}-\mathrm{OCH}_{3}\right)$; $\mathrm{MS}: 354.15\left(\mathrm{M}+\mathrm{H}^{+}\right)$. Anal. Calcd for $\mathrm{C}_{19} \mathrm{H}_{19} \mathrm{~N}_{3} \mathrm{O}_{4}$ : C, 64.58; H, 5.42; N, 11.89. Found: C, 64.71; H, 5.32; $\mathrm{N}, 12.03$.

4.2.6.3. $N$-Methoxy-1-(4'-methoxyphenyl)-3-(4"-methoxyphenyl)1H-pyrazole-4-carboxamide (6c). According to the general procedure, carboxamide $\mathbf{6 c}$ was obtained from carboxylic acid $\mathbf{5 c}$ as white solid (90\% yield). mp 187-188 ${ }^{\circ} \mathrm{C}$; IR (film) $v: 1659 \mathrm{~cm}^{-1}$; ${ }^{1} \mathrm{H}$ NMR (DMSO): $\delta=11.4(1 \mathrm{H}, \mathrm{s}, \mathrm{NH}), 8.72(1 \mathrm{H}, \mathrm{s}, \mathrm{H}-5), 7.82(4 \mathrm{H}$, d, $J 5.6 \mathrm{~Hz}, \mathrm{H}-2$ ', H-2" and H-6"), $7.12(2 \mathrm{H}, \mathrm{d}, J 6.0 \mathrm{~Hz}, \mathrm{H}-3$ " and H-5"), $7.02\left(2 \mathrm{H}, \mathrm{d}, J 6.0 \mathrm{~Hz}, \mathrm{H}-3\right.$ '), $3.83\left(9 \mathrm{H}, \mathrm{s}, \mathrm{OCH}_{3}\right) ;{ }^{13} \mathrm{C}$ NMR (DMSO): $\delta=161.4(\mathrm{CONH}), 159.8$ (C-4"), 158.5 (C-4'), 150.7 (C-3), 133.0 (C-1'), 130.1 (C-5), 129.7 (C-2" and C-6"), 125.0 (C-1"), 120.6 (C-2'), 115.2 (C-3" and C-5"), 114.0 (C-4 and C-3'), 63.73 $\left(\mathrm{NH}-\mathrm{OCH}_{3}\right), 55.92\left(\mathrm{C}^{\prime}-\mathrm{OCH}_{3}\right), 55.62\left(\mathrm{C}^{\prime \prime}-\mathrm{OCH}_{3}\right) ; \mathrm{MS}: 354.14$ $\left(\mathrm{M}+\mathrm{H}^{+}\right)$. Anal. Calcd for $\mathrm{C}_{19} \mathrm{H}_{19} \mathrm{~N}_{3} \mathrm{O}_{4}$ : C, 64.58; $\mathrm{H}, 5.42 ; \mathrm{N}, 11.89$. Found: C, 64.69; H, 5.35; N 12.00 .

4.2.6.4. N-Methoxy-1-(4'-methoxyphenyl)-3-(3",4"-dimethoxyphenyl)-1H-pyrazole-4-carboxamide (6d). According to the general procedure, carboxamide $\mathbf{6 d}$ was obtained from carboxylic acid 5d as white solid ( $85 \%$ yield). mp $193-194{ }^{\circ} \mathrm{C}$; IR (film) 
$v: 1650 \mathrm{~cm}^{-1} ;{ }^{1} \mathrm{H}$ NMR (DMSO): $\delta=11.5(1 \mathrm{H}, \mathrm{s}, \mathrm{NH}), 8.74(1 \mathrm{H}, \mathrm{s}, \mathrm{H}-$ 5), 7.83 (2H, d, $J 8.8 \mathrm{~Hz}, \mathrm{H}-2$ '), 7.55 (1H, s, H-2"), 7.45 (1H, dd, $J$ $8.4 \mathrm{HzJ} 2.0 \mathrm{~Hz}, \mathrm{H}-6$ "), 7.12 (2H, d, J $\left.8.8 \mathrm{~Hz}, \mathrm{H}-3^{\prime}\right), 7.04$ (1H, d, J $8.4 \mathrm{~Hz}, \mathrm{H}-5$ ") $3.83\left(9 \mathrm{H}, \mathrm{s}, \mathrm{C} 3\right.$ "'-OCH, $\mathrm{C}^{\prime \prime}-\mathrm{OCH}_{3}$, and $\left.\mathrm{NH}-\mathrm{OCH}_{3}\right)$, $3.74\left(3 \mathrm{H}, \mathrm{s}, \mathrm{C} 4^{\prime}-\mathrm{OCH}_{3}\right) ;{ }^{13} \mathrm{C}$ NMR (DMSO): $\delta=161.6(\mathrm{CONH}), 158.6$ (C-4'), 150.7 (C-3"), 149.5 (C-4"), 148.8 (C-3), 133.0 (C-1'), 130.2 (C-5), 125.3 (C-1"), 121.0 (C-6"), 120.7 (C-2'), 115.2 (C-3'), 114.3 (C-4), 112.2 (C-5"), 112.0 (C-2"), $63.72\left(\mathrm{NH}-\mathrm{OCH}_{3}\right), 55.94\left(\mathrm{OCH}_{3}\right)$; MS: $384.18\left(\mathrm{M}+\mathrm{H}^{+}\right)$. Anal. Calcd for $\mathrm{C}_{20} \mathrm{H}_{21} \mathrm{~N}_{3} \mathrm{O}_{5}$ : C, 62.65; $\mathrm{H}$, 5.52; N, 10.96. Found: C, 62.81; H, 5.39; N, 11.09.

4.2.6.5. N-Methoxy-1-(4'-methoxyphenyl)-3-(2",5"-dimethoxyphenyl)-1H-pyrazole-4-carboxamide (6e). According to the general procedure, carboxamide $\mathbf{6 e}$ was obtained from carboxylic acid 5e as white solid ( $80 \%$ yield). mp $177-178{ }^{\circ} \mathrm{C}$; IR (film) $v$ : $1651 \mathrm{~cm}^{-1}$; ${ }^{1} \mathrm{H}$ NMR (DMSO): $\delta=11.1(1 \mathrm{H}, \mathrm{s}, \mathrm{NH}), 8.62(1 \mathrm{H}, \mathrm{s}$, H-5), 7.77 (2H, d, J $\left.8.8 \mathrm{~Hz}, \mathrm{H}-2^{\prime}\right), 7.09$ (2H, d, J $\left.8.8 \mathrm{~Hz}, \mathrm{H}-3^{\prime}\right), 7.01$ $(1 \mathrm{H}, \mathrm{d}, J 2.8 \mathrm{~Hz}, \mathrm{H}-6$ "), $6.98-6.94(2 \mathrm{H}, \mathrm{m}, \mathrm{H}-3$ " and $\mathrm{H}-4$ "), 3.81 $\left(3 \mathrm{H}, \mathrm{s}, \mathrm{NH}-\mathrm{OCH}_{3}\right), 3.75\left(3 \mathrm{H}, \mathrm{s}, \mathrm{C2}\right.$ "'-OCH $\left.\mathrm{OCH}_{3}\right), 3.65\left(6 \mathrm{H}, \mathrm{s}, \mathrm{C}^{\prime}-\mathrm{OCH}_{3}\right.$ and $\left.\mathrm{C}^{\prime} "-\mathrm{OCH}_{3}\right) ;{ }^{13} \mathrm{C}$ NMR (DMSO): $\delta=161.5(\mathrm{CONH}), 158.5$ (C-4'), 153.3 (C-5"), 151.6 (C-2"), 149.0 (C-3), 133.2 (C-1'), 128.8 (C-5), 122.9 (C-1"), 120.8 (C-2'), 116.8 (C-4), 116.3 (C-4"), 115.2 (C-3'), 115.0 (C-3"), 112.7 (C-6"), $63.62\left(\mathrm{NH}-\mathrm{OCH}_{3}\right), 56.12\left(\mathrm{C}^{\prime}-\mathrm{OCH}_{3}\right)$, $55.97\left(\mathrm{C}^{\prime} "-\mathrm{OCH}_{3}\right), 55.94\left(\mathrm{C}^{\prime \prime}-\mathrm{OCH}_{3}\right)$; $\mathrm{MS}\left(\mathrm{M}+\mathrm{H}^{+}\right)$: 384.17. Anal. Calcd for $\mathrm{C}_{20} \mathrm{H}_{21} \mathrm{~N}_{3} \mathrm{O}_{5}$ : C, 62.65; $\mathrm{H}, 5.52 ; \mathrm{N}, 10.96$. Found: $\mathrm{C}$, 62.85; H, 5.62; N 10.87.

\subsubsection{Typical procedure for the cyclization of amides 6a-e with PIFA}

4.2.7.1 . Synthesis of 5-Methoxy-2-(4'-methoxyphenyl)-2H-pyrazolo[4,3-c]quinolin-4(5H)-one (7a). A solution of PIFA $(0.21 \mathrm{~g}$, $0.46 \mathrm{mmol})$ and TFA $(0.070 \mathrm{~mL}, 0.93 \mathrm{mmol})$ in $\mathrm{CH}_{2} \mathrm{Cl}_{2}(6.6 \mathrm{~mL})$ was added into a cold $\left(-20^{\circ} \mathrm{C}\right)$ solution of amide $\mathbf{6 a}(0.10 \mathrm{~g}$, $0.31 \mathrm{mmol})$ in $\mathrm{CH}_{2} \mathrm{Cl}_{2}(3.1 \mathrm{~mL})$. The mixture was stirred at the same temperature during $1 \mathrm{~h}$ until total consumption of the starting material and then quenched with $10 \%$ aq $\mathrm{Na}_{2} \mathrm{CO}_{3}$ and extracted twice with $\mathrm{CH}_{2} \mathrm{Cl}_{2}$. The combined organic extracts were washed with brine, dried with $\mathrm{Na}_{2} \mathrm{SO}_{4}$, filtered and evaporated. The product was obtained after flash column chromatography (Hex/EtOAc, 3:7) and evaporation of the solvent as white solid (57\% yield). mp 200$201{ }^{\circ} \mathrm{C}$; IR (film) $v: 1646 \mathrm{~cm}^{-1} ;{ }^{1} \mathrm{H} \mathrm{NMR}\left(\mathrm{CDCl}_{3}\right): \delta=8.68(1 \mathrm{H}, \mathrm{s}, \mathrm{H}-$ 3), $8.36(1 \mathrm{H}, \mathrm{d}, J 7.2 \mathrm{~Hz}, \mathrm{H}-9), 7.78(2 \mathrm{H}, \mathrm{d}, J 7.6 \mathrm{~Hz}, \mathrm{H}-2$ '), $7.66(1 \mathrm{H}, \mathrm{d}$, $J ~ 7.2 \mathrm{~Hz}, \mathrm{H}-6), 7.61(1 \mathrm{H}, \mathrm{t}, J 6.4 \mathrm{~Hz}, \mathrm{H}-7), 7.36(1 \mathrm{H}, \mathrm{t}, J 6.4 \mathrm{~Hz}, \mathrm{H}-8)$, $7.07\left(2 \mathrm{H}, \mathrm{d}, J 7.6 \mathrm{~Hz}, \mathrm{H}-3^{\prime}\right), 4.15\left(3 \mathrm{H}, \mathrm{s}, \mathrm{N}-\mathrm{OCH}_{3}\right), 3.90\left(3 \mathrm{H}, \mathrm{s}, \mathrm{C} 4{ }^{\prime}-\right.$ $\left.\mathrm{OCH}_{3}\right) ;{ }^{13} \mathrm{C} \mathrm{NMR}\left(\mathrm{CDCl}_{3}\right): \delta=159.5(\mathrm{C}-4), 155.1(\mathrm{C}-4), 148.0(\mathrm{C}-$ 1a), 136.9 (C-1'), 133.2 (C-5a), 130.0 (C-3), 127.4 (C-7), 123.3 (C9) 123.2 (C-8), 121.9 (C-2'), 114.8 (C-3' and C-9a), 113.0 (C-6 and C-3a) $62.95\left(\mathrm{~N}-O C H_{3}\right) 55.67\left(\mathrm{C}^{\prime}-\mathrm{OCH}_{3}\right)$; MS: $322.22\left(\mathrm{M}+\mathrm{H}^{+}\right)$. Anal. Calcd for $\mathrm{C}_{18} \mathrm{H}_{15} \mathrm{~N}_{3} \mathrm{O}_{3}$ : C, 67.28; $\mathrm{H}, 4.71 ; \mathrm{N}, 13.08$. Found: $\mathrm{C}, 67.41$; $\mathrm{H}, 4.59$; N 13.21.

4.2.7.2. 5,8-Dimethoxy-2-(4'-methoxyphenyl)-2H-pyrazolo[4,3c]quinolin-4(5H)-one (7b). According to the general procedure, pyrazoloquinolin-4-one $\mathbf{7 b}$ was obtained from carboxamide $\mathbf{6 b}$ after purification by flash column chromatography (Hex/EtOAc, 4:6) and evaporation of the solvent as white solid (55\% yield). mp 166$167{ }^{\circ} \mathrm{C}$; IR (film) $v: 1663 \mathrm{~cm}^{-1} ;{ }^{1} \mathrm{H} \mathrm{NMR}\left(\mathrm{CDCl}_{3}\right): \delta=8.66(1 \mathrm{H}, \mathrm{s}, \mathrm{H}-$ 3), $7.80(1 \mathrm{H}, \mathrm{d}, J 2.8 \mathrm{~Hz}, \mathrm{H}-9), 7.78(2 \mathrm{H}, \mathrm{d}, J 8.8 \mathrm{~Hz}, \mathrm{H}-2$ '), $7.57(1 \mathrm{H}$, d, $J 9.2 \mathrm{~Hz}, \mathrm{H}-6), 7.19(1 \mathrm{H}, \mathrm{dd}, J 9.2 \mathrm{~Hz} J 2.8 \mathrm{~Hz}, \mathrm{H}-7), 7.07(2 \mathrm{H}, \mathrm{d}, J$ $8.8 \mathrm{~Hz}, \mathrm{H}-3$ '), $4.13\left(3 \mathrm{H}, \mathrm{s}, \mathrm{N}-\mathrm{OCH}_{3}\right), 3.96\left(3 \mathrm{H}, \mathrm{s}, \mathrm{C} 8-\mathrm{OCH}_{3}\right), 3.90(3 \mathrm{H}$, s, $\left.\mathrm{C}^{\prime}-\mathrm{OCH}_{3}\right) ;{ }^{13} \mathrm{C}$ NMR $\left(\mathrm{CDCl}_{3}\right): \delta=159.5(\mathrm{C}-4), 155.8$ (C-8), 154.7 (C-4'), 147.8 (C-1a), 133.1 (C-1'), 131.1 (C-5a), 127.6 (C-3), 122.0 (C-2'), 118.4 (C-7), 115.5 (C-9a), 114.8 (C-3'), 114.6 (C-6), 114.3 (C3a), 105.5 (C-9), $62.97\left(\mathrm{~N}-\mathrm{OCH}_{3}\right), 55.90\left(\mathrm{C}^{\prime}-\mathrm{OCH}_{3}\right), 55.69(\mathrm{C} 8-$ $\left.\mathrm{OCH}_{3}\right)$; MS: $352.29\left(\mathrm{M}+\mathrm{H}^{+}\right)$. Anal. Calcd for $\mathrm{C}_{19} \mathrm{H}_{17} \mathrm{~N}_{3} \mathrm{O}_{4}$ : C, 64.95; H, 4.88; N, 11.96. Found: C, 65.10; H, 4.74; N 11.82 .
4.2.7.3. 5,7-Dimethoxy-2-(4'-methoxyphenyl)-2H-pyrazolo[4,3c]quinolin-4(5H)-one (7c). According to the general procedure, pyrazoloquinolin-4-one 7c was obtained from carboxamide $\mathbf{6 c}$ after purification by flash column chromatography (Hex/EtOAc, $3: 7)$ and evaporation of the solvent as white solid (55\% yield). mp 175-176 ${ }^{\circ} \mathrm{C}$; IR (film) $v: 1647 \mathrm{~cm}^{-1} ;{ }^{1} \mathrm{H}$ NMR $\left(\mathrm{CDCl}_{3}\right): \delta=8.63$ $(1 \mathrm{H}, \mathrm{s}, \mathrm{H}-3), 8.24(1 \mathrm{H}, \mathrm{d}, J 8.8 \mathrm{~Hz}, \mathrm{H}-9), 7.76(2 \mathrm{H}, \mathrm{d}, J 8.4 \mathrm{~Hz}, \mathrm{H}-$ 2'), $7.14(1 \mathrm{H}, \mathrm{s}, \mathrm{H}-6), 7.06(2 \mathrm{H}, \mathrm{d}, J 8.8 \mathrm{~Hz}, \mathrm{H}-3$ '), $6.94(1 \mathrm{H}, \mathrm{d}, J$ $8.8 \mathrm{~Hz}, \mathrm{H}-8), 4.14\left(3 \mathrm{H}, \mathrm{s}, \mathrm{N}-\mathrm{OCH}_{3}\right), 3.97\left(3 \mathrm{H}, \mathrm{s}, \mathrm{C} 7-\mathrm{OCH}_{3}\right), 3.91$ $\left(3 \mathrm{H}, \mathrm{s}, \mathrm{C} 4{ }^{\prime}-\mathrm{OCH}_{3}\right) ;{ }^{13} \mathrm{C}$ NMR $\left(\mathrm{CDCl}_{3}\right): \delta=161.5(\mathrm{C}-4), 159.4(\mathrm{C}-7)$, 155.5 (C-4'), 148.0 (C-1a), 138.4 (C-1'), 133.2 (C-5a), 127.4 (C-3), 124.7 (C-9), 121.9 (C-2'), 114.8 (C-3'), 113.0 (C-9a), 110.3 (C-8), 108.1 (C-3a), 97.70 (C-6) $62.88\left(\mathrm{~N}^{-} \mathrm{OCH}_{3}\right), 55.67\left(\mathrm{OCH}_{3}\right)$; MS: $352.28\left(\mathrm{M}+\mathrm{H}^{+}\right)$. Anal. Calcd for $\mathrm{C}_{19} \mathrm{H}_{17} \mathrm{~N}_{3} \mathrm{O}_{4}$ : C, 64.95; $\mathrm{H}, 4.88 ; \mathrm{N}$, 11.96. Found: C, 64.81; H, 4.78; N 12.08 .

4.2.7.4. 5,7,8-Trimethoxy-2-(4'-methoxyphenyl)-2H-pyrazolo[4,3-c]quinolin-4(5H)-one (7d). According to the general procedure, pyrazoloquinolin-4-one 7d was obtained from carboxamide 6d after purification by flash column chromatography (EtOAc) and evaporation of the solvent as yellowish oil ( $50 \%$ yield). IR (film) $v: 1655 \mathrm{~cm}^{-1} ;{ }^{1} \mathrm{H}$ NMR $\left(\mathrm{CDCl}_{3}\right): \delta=8.65(1 \mathrm{H}, \mathrm{s}, \mathrm{H}-3), 7.77(2 \mathrm{H}, \mathrm{d}, J$ $8.8 \mathrm{~Hz}, \mathrm{H}-2$ ') 7.75 (1H, s, H-9), $7.16(1 \mathrm{H}, \mathrm{s}, \mathrm{H}-6), 7.07$ (2H, d, J $8.8 \mathrm{~Hz}, \mathrm{H}-3$ ') $4.15\left(3 \mathrm{H}, \mathrm{s}, \mathrm{N}-\mathrm{OCH}_{3}\right), 4.06\left(3 \mathrm{H}, \mathrm{s}, \mathrm{C} 8-\mathrm{OCH}_{3}\right), 4.05$ $\left(3 \mathrm{H}, \mathrm{s}, \mathrm{C} 7-\mathrm{OCH}_{3}\right), 3.91\left(3 \mathrm{H}, \mathrm{s}, \mathrm{C}^{\prime}-\mathrm{OCH}_{3}\right) ;{ }^{13} \mathrm{C} \mathrm{NMR}\left(\mathrm{CDCl}_{3}\right)$ : $\delta=159.5$ (C-4), 155.0 (C-4'), 151.4 (C-8), 148.0 (C-1a), 145.9 (C-7), 133.2 (C-1'), 131.9 (C-3), 127.5 (C-5a), 122.0 (C-2'), 114.8 (C-3'), 113.5 (C-9a), 107.1 (C-3a), 104.9 (C-9), 96.58 (C-6), 62.92 $\left(\mathrm{N}-\mathrm{OCH}_{3}\right), 56.42\left(\mathrm{C}^{2}-\mathrm{OCH}_{3}\right), 56.29\left(\mathrm{C} 8-\mathrm{OCH}_{3}\right), 55.66\left(\mathrm{C}^{\prime}-\mathrm{OCH}_{3}\right)$; MS: $382.31\left(\mathrm{M}+\mathrm{H}^{+}\right)$. Anal. Calcd for $\mathrm{C}_{20} \mathrm{H}_{19} \mathrm{~N}_{3} \mathrm{O}_{5}$ : C, 62.99; $\mathrm{H}$, 5.02; N, 11.02. Found: C, 63.10; H, 4.94; N 10.98 .

4.2.7.5. 5,6,9-Trimethoxy-2-(4'-methoxyphenyl)-2H-pyrazolo[4,3-c]quinolin-4(5H)-one (7e). According to the general procedure, pyrazoloquinolin-4-one 7e was obtained from carboxamide 6e after purification by flash column chromatography (EtOAc) and evaporation of the solvent as yellowish oil ( $50 \%$ yield). IR (film) $v: 1656 \mathrm{~cm}^{-1} ;{ }^{1} \mathrm{H}$ NMR $\left(\mathrm{CDCl}_{3}\right): \delta=8.67(1 \mathrm{H}, \mathrm{s}, \mathrm{H}-3), 7.89(2 \mathrm{H}, \mathrm{d}, J$ $9.2 \mathrm{~Hz}, \mathrm{H}-2$ '), $7.76(1 \mathrm{H}, \mathrm{d}, J 8.8 \mathrm{~Hz}, \mathrm{H}-7), 7.18(1 \mathrm{H}, \mathrm{d}, J 8.8 \mathrm{~Hz}, \mathrm{H}-8)$, $7.03\left(2 \mathrm{H}, \mathrm{d}, J 9.2 \mathrm{~Hz}, \mathrm{H}-3\right.$ '), $4.17\left(3 \mathrm{H}, \mathrm{s}, \mathrm{N}-\mathrm{OCH}_{3}\right), 3.96(3 \mathrm{H}, \mathrm{s}, \mathrm{C} 6-$ $\left.\mathrm{OCH}_{3}\right), 3.91\left(3 \mathrm{H}, \mathrm{s}, \mathrm{C} 9-\mathrm{OCH}_{3}\right), 3.91\left(3 \mathrm{H}, \mathrm{s}, \mathrm{C}^{\prime}-\mathrm{OCH}_{3}\right) ;{ }^{13} \mathrm{C} \mathrm{NMR}$ $\left(\mathrm{CDCl}_{3}\right): \delta=160.1$ (C-4), 159.7 (C-4'), 159.6 (C-6), 139.4 (C-1a), 139.3 (C-9), 133.3 (C-1'), 133.0 (C-3), 127.0 (C-5a), 122.4 (C-2') 115.1 (C-3'), 114.8 (C-7), 114.6 (C-3a), 111.9 (C-9a), 106.4 (C-8), $63.12\left(\mathrm{~N}-\mathrm{OCH}_{3}\right), 55.87\left(\mathrm{C} 9-\mathrm{OCH}_{3}\right), 55.66\left(\mathrm{C} 6-\mathrm{OCH}_{3}\right), 52.22\left(\mathrm{C} 4{ }^{\prime}-\right.$ $\left.\mathrm{OCH}_{3}\right)$; MS: $382.33\left(\mathrm{M}+\mathrm{H}^{+}\right)$. Anal. Calcd for $\mathrm{C}_{20} \mathrm{H}_{19} \mathrm{~N}_{3} \mathrm{O}_{5}$ : C, 62.99; H, 5.02; N, 11.02. Found: C, 63.14; H, 4.90; N 10.89 .

4.2.8. General procedure for the demethylation of pyrazoloquinolin-4-ones 7a-e

4.2.8.1. Synthesis of 5-Hydroxy-2-(4'-hydroxyphenyl)-2H-pyrazolo[4,3-c]quinolin-4(5H)-one (8a). To a stirred solution of the protected pyrazoloquinolin-4-one $7 \mathrm{a}(0.050 \mathrm{~g}, 0.16 \mathrm{mmol})$ in $\mathrm{CH}_{2} \mathrm{Cl}_{2}(5.0 \mathrm{~mL})$ at $-78{ }^{\circ} \mathrm{C} \mathrm{BBr}_{3}$ (1.6 mmol, $1.0 \mathrm{M}$ in $\mathrm{CH}_{2} \mathrm{Cl}_{2}, 5$ equiv per bond, $1.6 \mathrm{~mL}$ ) was added dropwise. The reaction was kept at $78{ }^{\circ} \mathrm{C}$ for $1 \mathrm{~h}$ and then for $16 \mathrm{~h}$ at room temperature. The solution was cooled at $0^{\circ} \mathrm{C}$, neutralized with $\mathrm{MeOH}$ and then $\mathrm{HCl} 1 \mathrm{~N}$ was added. The organic phase was extracted twice with EtOAc. The combined organic extracts were washed with water, brine, dried with $\mathrm{Na}_{2} \mathrm{SO}_{4}$, filtered and evaporated. The product was obtained after flash column chromatography (EtOAc) and evaporation of the solvent as brown solid (95\% yield). $\mathrm{mp} 269-270{ }^{\circ} \mathrm{C}$; IR (film) $v$ : 3390, $1642 \mathrm{~cm}^{-1}$; ${ }^{1} \mathrm{H}$ NMR (DMSO): $\delta=11.0(1 \mathrm{H}, \mathrm{s}, \mathrm{N}-\mathrm{OH})$, $9.90\left(1 \mathrm{H}, \mathrm{s}, \mathrm{C} 4{ }^{\prime}-\mathrm{OH}\right) 9.30(1 \mathrm{H}, \mathrm{s}, \mathrm{H}-3), 8.19(1 \mathrm{H}, \mathrm{d}, J \mathrm{~J} 7.2 \mathrm{~Hz}, \mathrm{H}-9)$, $7.89(2 \mathrm{H}, \mathrm{d}, J 8.0 \mathrm{~Hz}, \mathrm{H}-2$ '), $7.73(1 \mathrm{H}, \mathrm{d}, J 8.0 \mathrm{~Hz}, \mathrm{H}-6), 7.62(1 \mathrm{H}$, t, $J 6.8 \mathrm{~Hz}, \mathrm{H}-7), 7.34(1 \mathrm{H}, \mathrm{t}, J 6.8 \mathrm{~Hz}, \mathrm{H}-8), 6.95(2 \mathrm{H}, \mathrm{d}, J 8.0 \mathrm{~Hz}$, 
H-3'); ${ }^{13} \mathrm{C}$ NMR (DMSO): $\delta=157.7$ (C-4), 155.1 (C-4'), 147.0 (C-1a), 138.8 (C-1'), 131.9 (C-5a), 130.3 (C-3), 128.4 (C-7), 123.0 (C-9) 122.7 (C-8), 122.0 (C-2'), 116.4 (C-3’) 114.1 (C-9a) 113.9 (C-6) 113.8 (C-3a); MS: $294.17\left(\mathrm{M}+\mathrm{H}^{+}\right)$. Anal. Calcd for $\mathrm{C}_{16} \mathrm{H}_{11^{-}}$ $\mathrm{N}_{3} \mathrm{O}_{3}$ : C, 65.53; $\mathrm{H}, 3.78 ; \mathrm{N}, 14.33$. Found: C, 65.39; H, 3.86; N 14.46 .

4.2.8.2. 5,8-Dihydroxy-2-(4'-hydroxyphenyl)-2H-pyrazolo[4,3-c] quinolin-4-one (8b). According to the general procedure, demethylated pyrazoloquinolin-4-one $\mathbf{8 b}$ was obtained from pyrazoloquinolin-4-one $\mathbf{7 b}$ after purification by flash column chromatography (EtOAc) and evaporation of the solvent as yellowish oil (95\% yield). IR (film) $v$ : 3416, $1652 \mathrm{~cm}^{-1} ;{ }^{1} \mathrm{H}$ NMR (DMSO): $\delta=10.94$ $(1 \mathrm{H}, \mathrm{s}, \mathrm{N}-\mathrm{OH}), 9.94(1 \mathrm{H}, \mathrm{s}, \mathrm{OH}), 9.70(1 \mathrm{H}, \mathrm{s}, \mathrm{OH}), 9.23(1 \mathrm{H}, \mathrm{s}, \mathrm{H}-3)$, $7.87(2 \mathrm{H}, \mathrm{d}, J 7.2 \mathrm{~Hz}, \mathrm{H}-2$ '), 7.56 (1H, d, J $8.0 \mathrm{~Hz}, \mathrm{H}-6), 7.07$ (1H, d, $J$ $8.0 \mathrm{~Hz}, \mathrm{H}-7), 6.95$ (2H, d, J 7.2 Hz, H-3'), 6.58 (1H, s, H-9); ${ }^{13} \mathrm{C}$ NMR (DMSO): $\delta=157.8$ (C-4), 157.7 (C-8), 153.4 (C-4'), 146.9 (C-1a), 132.1 (C-1'), 132.0 (C-5a), 128.3 (C-3), 122.0 (C-2'), 118.5 (C-9a), 116.4 (C-3'), 115.7 (C-7), 114.8 (C-6), 114.2 (C-3a), 107.4 (C-9); MS: $310.39\left(\mathrm{M}+\mathrm{H}^{+}\right)$. Anal. Calcd for $\mathrm{C}_{16} \mathrm{H}_{11} \mathrm{~N}_{3} \mathrm{O}_{4}$ : C, 62.14; $\mathrm{H}, 3.58$; N, 13.59. Found: C, 62.27 ;, $3.67 ; \mathrm{N} 13.48$.

4.2.8.3. 5,7-Dihydroxy-2-(4'-hydroxyphenyl)-2H-pyrazolo[4,3-c]quinolin-4(5H)-one (8c). According to the general procedure, demethylated pyrazoloquinolin-4-one $8 c$ was obtained from pyrazoloquinolin-4-one $7 \mathrm{c}$ after purification by flash column chromatography (EtOAc) and evaporation of the solvent as yellowish oil (95\% yield). IR (film) $v: 3381,1635 \mathrm{~cm}^{-1} ;{ }^{1} \mathrm{H}$ NMR (acetone-d6): $\delta=9.10(1 \mathrm{H}, \mathrm{s}, \mathrm{N}-\mathrm{OH}), 8.94(1 \mathrm{H}, \mathrm{s}, \mathrm{OH}), 8.92(1 \mathrm{H}, \mathrm{s}, \mathrm{H}-3), 8.86$ (1H, s, OH), 8.12 (1H, d, J $8.4 \mathrm{~Hz}, \mathrm{H}-9), 7.90(2 \mathrm{H}, \mathrm{d}, J 8.4 \mathrm{~Hz}, \mathrm{H}-2$ '), $7.31(1 \mathrm{H}, \mathrm{s}, \mathrm{H}-6), 7.04(2 \mathrm{H}, \mathrm{d}, J 8.0 \mathrm{~Hz}, \mathrm{H}-3$ '), $6.90(1 \mathrm{H}, \mathrm{d}, J 8.4 \mathrm{~Hz}$, $\mathrm{H}-8) ;{ }^{13} \mathrm{C}$ NMR (acetone-d6): $\delta=159.2$ (C-4), 157.2 (C-7), 154.6 (C-4'), 147.5 (C-1a), 138.6 (C-1'), 132.5 (C-5a), 126.7 (C-3), 124.1 (C-9), 121.6 (C-2'), 115.9 (C-3'), 111.7 (C-9a), 111.1 (C-8), 106.5 (C-3a), 99.39 (C-6); MS: $310.37\left(\mathrm{M}+\mathrm{H}^{+}\right)$. Anal. Calcd for $\mathrm{C}_{16} \mathrm{H}_{11} \mathrm{~N}_{3} \mathrm{O}_{4}$ : C, 62.14; H, 3.58; N, 13.59. Found: C, 61.96; H, 3.69; $\mathrm{N} 13.44$.

4.2.8.4. 5,7,8-Trihydroxy-2-(4'-hydroxyphenyl)-2H-pyrazolo[4,3c]quinolin-4(5H)-one $(\mathbf{8 d})$. According to the general procedure, demethylated pyrazoloquinolin-4-one $8 \mathrm{~d}$ was obtained from pyrazoloquinolin-4-one $7 \mathrm{~d}$ after purification by flash column chromatography (EtOAc) and evaporation of the solvent as yellowish oil (90\% yield). IR (film) $v$ : 3398, $1650 \mathrm{~cm}^{-1} ;{ }^{1} \mathrm{H}$ NMR (DMSO): $\delta=9.14(1 \mathrm{H}, \mathrm{s}, \mathrm{H}-3), 7.84(2 \mathrm{H}, \mathrm{d}, J 8.8 \mathrm{~Hz}, \mathrm{H}-2$ '), 7.48 (1H, s, H-9), $7.13(1 \mathrm{H}, \mathrm{s}, \mathrm{H}-6), 6.92\left(2 \mathrm{H}, \mathrm{d}, J 8.8 \mathrm{~Hz}, \mathrm{H}-3\right.$ '); ${ }^{13} \mathrm{C}$ NMR (DMSO): $\delta=157.4(\mathrm{C}-4), 154.9$ (C-4'), 152.0 (C-8), 148.6 (C-1a), 142.2 (C7), 133.0 (C-1'), 132.0 (C-3), 127.9 (C-5a), 121.8 (C-2'), 116.4 (C-3' and C-9a), 108.2 (C-3a), 105.6 (C-9), 101.2 (C-6); MS: 326.28 $\left(\mathrm{M}+\mathrm{H}^{+}\right)$. Anal. Calcd for $\mathrm{C}_{16} \mathrm{H}_{11} \mathrm{~N}_{3} \mathrm{O}_{5}$ : C, 59.08; $\mathrm{H}, 3.41 ; \mathrm{N}, 12.92$. Found: C, 59.23; H, 3.49; N 13.07.

4.2.8.5. 5,6,9-Trihydroxy-2-(4'-hydroxyphenyl)-2H-pyrazolo[4,3c]quinolin-4(5H)-one $(8 \mathrm{e})$. According to the general procedure, demethylated pyrazoloquinolin-4-one $8 \mathrm{e}$ was obtained from pyrazoloquinolin-4-one 7e after purification by flash column chromatography (EtOAc) and evaporation of the solvent as yellowish oil (90\% yield). IR (film) $v$ : 3412, $1652 \mathrm{~cm}^{-1} ;{ }^{1} \mathrm{H}$ NMR (DMSO): $\delta=9.24(1 \mathrm{H}, \mathrm{s}, \mathrm{H}-3), 7.90(2 \mathrm{H}, \mathrm{d}, J 8.8 \mathrm{~Hz}, \mathrm{H}-2), 7.63(1 \mathrm{H}, \mathrm{d}, J$ $8.4 \mathrm{~Hz}, \mathrm{H}-7), 7.13(1 \mathrm{H}, \mathrm{d}, J 8.4 \mathrm{~Hz}, \mathrm{H}-8), 6.95(2 \mathrm{H}, \mathrm{d}, J 8.8 \mathrm{~Hz}, \mathrm{H}-$ $3^{\prime}$ ); ${ }^{13} \mathrm{C}$ NMR (DMSO): $\delta=157.2$ (C-4), 155.3 (C-4'), 153.4 (C-6), 142.4 (C-1a), 139.3 (C-9), 133.1 (C-1'), 132.8 (C-3), 127.3 (C-5a), 122.1 (C-2'), 115.3 (C-3'), 115.0 (C-7), 114.6 (C-3a), 111.9 (C-9a), 106.4 (C-8); MS: $326.29\left(\mathrm{M}+\mathrm{H}^{+}\right)$. Anal. Calcd for $\mathrm{C}_{16} \mathrm{H}_{11} \mathrm{~N}_{3} \mathrm{O}_{5}$ : C, 59.08; H, 3.41; N, 12.92. Found: C, 58.89; H, 3.53; N 12.79.
4.2.9. General procedure for the synthesis of esters 9a-e 4.2.9.1. Synthesis of (E)-ethyl 3-(1'-(4"-methoxyphenyl)-3'-phenyl-1'H-pyrazol-4'-yl) acrylate (9a). To a stirred solution of the protected aldehyde $3 \mathrm{a}(1.2 \mathrm{~g}, 4.3 \mathrm{mmol})$ in $\mathrm{MeCN}(14 \mathrm{~mL})$, $\mathrm{Ph}_{3} \mathrm{PCHCO}_{2} \mathrm{CH}_{2} \mathrm{CH}_{3}(1.6 \mathrm{~g}, 4.7 \mathrm{mmol})$ was added and the reaction mixture was refluxed overnight. After the completion of the reaction EtOAc was added and the organic layer was washed with water, brine, dried with $\mathrm{Na}_{2} \mathrm{SO}_{4}$, filtered and evaporated. The product was obtained after flash column chromatography (Hex/EtOAc, $8: 2$ ) and evaporation of the solvent as white solid (90\% yield). mp 162-163 ${ }^{\circ} \mathrm{C}$; IR (film) $v: 1703 \mathrm{~cm}^{-1} ;{ }^{1} \mathrm{H} \mathrm{NMR}\left(\mathrm{CDCl}_{3}\right): \delta=8.16$ (1H, s, H-5'), 7.76 (1H, d, J 16 Hz, H-3), 7.69 (2H, d, J 7.2 Hz, H-2"' and H-6"'), 7.68 (2H, d, J $8.8 \mathrm{~Hz}, \mathrm{H}-2$ "), $7.51(2 \mathrm{H}, \mathrm{t}, J$ 7.2 Hz, H-3"' and H-5"'), 7.45 (1H, t, J $7.2 \mathrm{~Hz}, \mathrm{H}-4$ "'), $7.02(2 \mathrm{H}, \mathrm{d}, J 8.8 \mathrm{~Hz}, \mathrm{H}-$ 3"), $6.28(1 \mathrm{H}, \mathrm{d}, J 16 \mathrm{~Hz}, \mathrm{H}-2), 4.26\left(2 \mathrm{H}, \mathrm{q}, J 7.2 \mathrm{~Hz}, \mathrm{OCH}_{2} \mathrm{CH}_{3}\right)$, $3.88\left(3 \mathrm{H}, \mathrm{s}, \mathrm{OCH}_{3}\right), 1.34\left(3 \mathrm{H}, \mathrm{t}, J 7.2 \mathrm{~Hz}, \mathrm{OCH}_{2} \mathrm{CH}_{3}\right) ;{ }^{13} \mathrm{C} \mathrm{NMR}$ $\left(\mathrm{CDCl}_{3}\right)$ : 167.1 (C-1), 158.8 (C-4"), 153.0 (C-3'), 135.2 (C-4'), 133.2 (C-1"), 132.4 (C-1"'), 128.7 (C-3, C-3"' and C-5"'), 128.6 (C-2"' and C-6"'), 128.5 (C-4"'), 126.4 (C-5'), 121.0 (C-2"), 117.3 (C-2), 114.6 (C-3"), $60.32\left(\mathrm{OCH}_{2} \mathrm{CH}_{3}\right), 55.60\left(\mathrm{OCH}_{3}\right), 14.35\left(\mathrm{OCH}_{2} \mathrm{CH}_{3}\right)$; MS: 349.28 $\left(\mathrm{M}+\mathrm{H}^{+}\right)$. Anal. Calcd for $\mathrm{C}_{21} \mathrm{H}_{20} \mathrm{~N}_{2} \mathrm{O}_{3}$ : C, 72.40; H, 5.79; N, 8.04. Found: C, 72.19; H, 5.69; N 8.20.

4.2.9.2. (E)-ethyl 3-(1'-(4"-methoxyphenyl)-3'-(3"'-methoxyphenyl)-1'H-pyrazol-4'-yl) acrylate (9b). According to the general procedure, ester $9 \mathrm{~b}$ was obtained from aldehyde $3 \mathrm{~b}$ after purification by flash column chromatography (Hex/EtOAc, 7:3) and evaporation of the solvent as white solid (80\% yield). mp 119-120 ${ }^{\circ} \mathrm{C}$; IR (film) $v$ : $1703 \mathrm{~cm}^{-1} ;{ }^{1} \mathrm{H}$ NMR $\left(\mathrm{CDCl}_{3}\right): \delta=8.15$ $\left(1 \mathrm{H}, \mathrm{s}, \mathrm{H}-5^{\prime}\right), 7.76(1 \mathrm{H}, \mathrm{d}, J 16 \mathrm{~Hz}, \mathrm{H}-3), 7.68(2 \mathrm{H}, \mathrm{d}, J 8.8 \mathrm{~Hz}, \mathrm{H}-$ 2"), $7.41(1 \mathrm{H}, \mathrm{t}, J 8.0 \mathrm{~Hz}, \mathrm{H}-5$ "'), $7.25(2 \mathrm{H}, \mathrm{d}, J 6.4 \mathrm{~Hz}, \mathrm{H}-2$ "' and H-6"'), 7.00 (3H, d, J $8.8 \mathrm{~Hz}, \mathrm{H}-3$ " and H-4"'), 6.28 (1H, d, $J 16 \mathrm{~Hz}$, $\mathrm{H}-2), 4.26\left(2 \mathrm{H}, \mathrm{q}, J 7.2 \mathrm{~Hz}, \mathrm{OCH}_{2} \mathrm{CH}_{3}\right), 3.89\left(3 \mathrm{H}, \mathrm{s}, \mathrm{C} 3\right.$ "'- $\left.-\mathrm{OCH}_{3}\right)$, $3.86\left(3 \mathrm{H}, \mathrm{s}, \mathrm{C} 4 "-\mathrm{OCH}_{3}\right), 1.33\left(3 \mathrm{H}, \mathrm{t}, J 7.2 \mathrm{~Hz}, \mathrm{OCH}_{2} \mathrm{CH}_{3}\right) ;{ }^{13} \mathrm{C} \mathrm{NMR}$ $\left(\mathrm{CDCl}_{3}\right)$ : 167.0 (C-1), 159.8 (C-3"'), 158.8 (C-4"), 152.8 (C-3'), 135.2 (C-4'), 133.6 (C-1"), 133.2 (C-1"”), 129.7 (C-3), 126.4 (C-5”'), 121.2 (C-5'), 121.0 (C-2"), 117.3 (C-4"' and C-6"'), 114.6 (C-3" and C-2"'), 113.7 (C-2), $60.31\left(\mathrm{OCH}_{2} \mathrm{CH}_{3}\right), 55.60\left(\mathrm{C}^{\prime \prime}-\mathrm{OCH}_{3}\right), 55.36$ $\left(\mathrm{C} 3\right.$ '"- $\left.-\mathrm{OCH}_{3}\right), 14.36\left(\mathrm{OCH}_{2} \mathrm{CH}_{3}\right)$; MS: $379.14\left(\mathrm{M}+\mathrm{H}^{+}\right)$. Anal. Calcd for $\mathrm{C}_{22} \mathrm{H}_{22} \mathrm{~N}_{2} \mathrm{O}_{4}$ : C, 69.83; H, 5.86; N, 7.40. Found: C, 70.01; $\mathrm{H}$, 5.73; N 7.53.

4.2.9.3. (E)-ethyl 3-(1'-(4"-methoxyphenyl)-3'-(4"'-methoxyphenyl)-1'H-pyrazol-4'-yl) acrylate (9c). According to the general procedure, ester 9c was obtained from aldehyde $3 c$ after purification by flash column chromatography (Hex/EtOAc, 7:3) and evaporation of the solvent as foam (80\% yield). IR (film) $v$ : $1703 \mathrm{~cm}^{-1} ;{ }^{1} \mathrm{H}$ NMR $\left(\mathrm{CDCl}_{3}\right): \delta=8.13(1 \mathrm{H}, \mathrm{s}, \mathrm{H}-5), 7.74(1 \mathrm{H}, \mathrm{d}, J$ $16 \mathrm{~Hz}, \mathrm{H}-3), 7.67$ (2H, d, J 9.2 Hz, H-2"' and H-6"'), $7.62(2 \mathrm{H}, \mathrm{d}, J$ $8.8 \mathrm{~Hz}, \mathrm{H}-2$ "), 7.03 (2H, d, $J 9.2 \mathrm{~Hz}, \mathrm{H}-3$ "' and H-5"'),7.01(2H, d, $J$ $8.8 \mathrm{~Hz}, \mathrm{H}-3$ ") $, 6.27(1 \mathrm{H}, \mathrm{d}, J 16 \mathrm{~Hz}, \mathrm{H}-2), 4.26(2 \mathrm{H}, \mathrm{q}, J 7.2 \mathrm{~Hz}$, $\left.\mathrm{OCH}_{2} \mathrm{CH}_{3}\right), 3.89\left(3 \mathrm{H}, \mathrm{s}, \mathrm{C} 4\right.$ "'- $\left.-\mathrm{OCH}_{3}\right), 3.88\left(3 \mathrm{H}, \mathrm{s}, \mathrm{C}^{\prime}\right.$ "'-OCH $\left.\mathrm{OCH}_{3}\right), 1.34$ $\left(3 \mathrm{H}, \mathrm{t}, J 7.2 \mathrm{~Hz}, \mathrm{OCH}_{2} \mathrm{CH}_{3}\right) ;{ }^{13} \mathrm{C}$ NMR $\left(\mathrm{CDCl}_{3}\right): 167.2(\mathrm{C}-1), 160.0$ (C-4"'), 158.7 (C-4"), 152.8 (C-3'), 135.4 (C-4'), 133.2 (C-1"), 129.9 (C-2"' and C-6"'), 126.3 (C-3), 124.9 (C-1"'), 121.0 (C-2"), 117.1 (C-5'), 117.0 (C-2), 114.6 (C-3"' and C-5"), 114.2 (C-3"), 60.29 $\left(\mathrm{OCH}_{2} \mathrm{CH}_{3}\right), \quad 55.60 \quad\left(\mathrm{C} 4{ }^{\prime \prime}-\mathrm{OCH}_{3}\right), \quad 55.35\left(\mathrm{C}^{\prime \prime \prime}-\mathrm{OCH}_{3}\right), \quad 14.34$ $\left(\mathrm{OCH}_{2} \mathrm{CH}_{3}\right)$; MS: $379.20\left(\mathrm{M}+\mathrm{H}^{+}\right)$. Anal. Calcd for $\mathrm{C}_{22} \mathrm{H}_{22} \mathrm{~N}_{2} \mathrm{O}_{4}$ : C, 69.83; H, 5.86; N, 7.40. Found: C, 69.99; H, 5.99; N 7.55.

4.2.9.4. (E)-ethyl 3-(1'-(4"'-methoxyphenyl)-3'-(3"',4"'-dimethoxyphenyl)- 1'H-pyrazol-4'-yl) acrylate (9d). According to the general procedure, ester 9d was obtained from aldehyde $3 d$ after purification by flash column chromatography (Hex/EtOAc, $1: 1)$ and evaporation of the solvent as white solid (80\% yield). mp 122-123 ${ }^{\circ} \mathrm{C}$; IR (film) $v: 1704 \mathrm{~cm}^{-1} ;{ }^{1} \mathrm{H} \mathrm{NMR}\left(\mathrm{CDCl}_{3}\right): \delta=8.13$ 
(1H, s, H-5'), 7.76 (1H, d, J 16 Hz, H-3), 7.67 (2H, d, J 9.2 Hz, H-2”), 7.24 (1H, d, J $2.0 \mathrm{~Hz}, \mathrm{H}-2$ '”), 7.20 (1H, dd, J $8.2 \mathrm{~Hz} J 2.0 \mathrm{~Hz}, \mathrm{H}-6$ '”), 7.00 (2H, d, J 9.2 Hz, H-3"), 6.99 (1H, d, J $8.2 \mathrm{~Hz}, \mathrm{H}-5$ '”), 6.27 (1H, d, J $16 \mathrm{~Hz}, \mathrm{H}-2), 4.25\left(2 \mathrm{H}, \mathrm{q}, J 7.2 \mathrm{~Hz}, \mathrm{OCH}_{2} \mathrm{CH}_{3}\right), 3.97(3 \mathrm{H}, \mathrm{s}, \mathrm{C} 3$ '”-

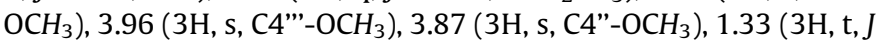
$\left.7.2 \mathrm{~Hz}, \mathrm{OCH}_{2} \mathrm{CH}_{3}\right) ;{ }^{13} \mathrm{C}$ NMR $\left(\mathrm{CDCl}_{3}\right): 167.1$ (C-1), 158.8 (C-4"), 152.8 (C-3'), 149.5 (C-3"'), 149.2 (C-4"'), 135.4 (C-4'), 133.2 (C-1"), 126.4 (C-1"'), 125.1 (C-3), 121.4 (C-5'), 121.0 (C-2"), 120.9 (C-6”) 117.1 (C-5"”), 114.6 (C-3"), 111.6 (C-2"”), 111.3 (C-2), 60.29

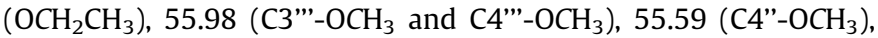
$14.35\left(\mathrm{OCH}_{2} \mathrm{CH}_{3}\right)$; MS: $409.34\left(\mathrm{M}+\mathrm{H}^{+}\right)$. Anal. Calcd for $\mathrm{C}_{23} \mathrm{H}_{24} \mathrm{~N}_{2} \mathrm{O}_{5}$ : C, 67.63; H, 5.92; N, 6.86. Found: C, 67.71; H, 5.83; N 6.94.

4.2.9.5. (E)-ethyl 3-1'-(4"-methoxyphenyl)-3'-(2"',5"'-dimethoxyphenyl)-1'H-pyrazol-4'-yl) acrylate (9e). According to the general procedure, ester 9e was obtained from aldehyde $3 e$ after purification by flash column chromatography (Hex/EtOAc, 7:3) and evaporation of the solvent as white solid ( $80 \%$ yield). $\mathrm{mp} 116-117{ }^{\circ} \mathrm{C}$; IR (film) $v$ : $1704 \mathrm{~cm}^{-1} ;{ }^{1} \mathrm{H}$ NMR (DMSO): $\delta=8.14(1 \mathrm{H}, \mathrm{s}, \mathrm{H}-5$ '), $7.69(2 \mathrm{H}, \mathrm{d}, J$ $9.2 \mathrm{~Hz}, \mathrm{H}-2$ "), $7.68(1 \mathrm{H}, \mathrm{d}, J 16 \mathrm{~Hz}, \mathrm{H}-3), 7.08(1 \mathrm{H}, \mathrm{d}, J 1.6 \mathrm{~Hz}$, H-6"'), 7.00 (2H, d, J 9.2 Hz, H-3"), 6.97 (2H, d, J 8.8 Hz, H-3"' and $\mathrm{H}-4$ "'), $6.12(1 \mathrm{H}, \mathrm{d}, J 16 \mathrm{~Hz}, \mathrm{H}-2), 4.22\left(2 \mathrm{H}, \mathrm{q}, J 7.2 \mathrm{~Hz}, \mathrm{OCH}_{2} \mathrm{CH}_{3}\right)$, $3.87\left(3 \mathrm{H}, \mathrm{s}, \mathrm{C} 5\right.$ '”- $\left.\mathrm{OCH}_{3}\right), 3.83\left(3 \mathrm{H}, \mathrm{s}, \mathrm{C} 2\right.$ '”- $\left.-\mathrm{OCH}_{3}\right), 3.80(3 \mathrm{H}, \mathrm{s}$, $\left.\mathrm{C}^{\prime \prime}-\mathrm{OCH}_{3}\right), 1.21\left(3 \mathrm{H}, \mathrm{t}, J 7.2 \mathrm{~Hz}, \mathrm{OCH}_{2} \mathrm{CH}_{3}\right) ;{ }^{13} \mathrm{C}$ NMR (DMSO): 167.3 (C-1), 158.7 (C-4"), 153.7 (C-5”'), 151.4 (C-2"'), 150.6 (C-3'), 136.0 (C-4'), 133.6 (C-1"), 133.3 (C-3), 126.0 (C-5') 121.0 (C-2"), 118.7 (C-1"') 116.7 (C-4"'), 116.0 (C-3"'), 115.8 (C-6”'), 114.6 (C-3"), 112.6 (C-2) $60.12\left(\mathrm{OCH}_{2} \mathrm{CH}_{3}\right), 56.11\left(\mathrm{C}^{\prime \prime}-\mathrm{OCH}_{3}\right) 55.86$ $\left(\mathrm{C} 5\right.$ "'-OCH $\left.\mathrm{OCH}_{3}\right) 55.58\left(\mathrm{C} 2^{\prime \prime}-\mathrm{OCH}_{3}\right)$, , 14.35 $\left(\mathrm{OCH}_{2} \mathrm{CH}_{3}\right)$; MS: 409.35 $\left(\mathrm{M}+\mathrm{H}^{+}\right)$. Anal. Calcd for $\mathrm{C}_{23} \mathrm{H}_{24} \mathrm{~N}_{2} \mathrm{O}_{5}$ : C, 67.63; H, 5.92; N, 6.86. Found: C, 67.85; H, 5.78; N 7.01.

4.2.10. General procedure for the demethylation of esters 9a-e 4.2.10.1. Synthesis of (E)-ethyl 3-(1'-(4"-hydroxyphenyl)-3'-phenyl-1'H-pyrazol-4'-yl) acrylate (10a). To a stirred solution of the protected ester 9a $(0.20 \mathrm{~g}, 0.57 \mathrm{mmol})$ in $\mathrm{CH}_{2} \mathrm{Cl}_{2}(18 \mathrm{~mL})$ at $-78{ }^{\circ} \mathrm{C}$ $\mathrm{BBr}_{3}$ (2.8 mmol, $1.0 \mathrm{M}$ in $\mathrm{CH}_{2} \mathrm{Cl}_{2}$, 5 equiv per bond, $2.8 \mathrm{~mL}$ ) was added dropwise. The reaction was kept at $-78^{\circ} \mathrm{C}$ for $1 \mathrm{~h}$ and then for $16 \mathrm{~h}$ at room temperature. The solution was cooled at $0{ }^{\circ} \mathrm{C}$, neutralized with $\mathrm{MeOH}$ and then $\mathrm{HCl} 1 \mathrm{~N}$ was added. The organic phase was extracted twice with EtOAc. The combined organic extracts were washed with water, brine, dried with $\mathrm{Na}_{2} \mathrm{SO}_{4}$, filtered and evaporated. The product was obtained after flash column chromatography (Hex/EtOAc, 1:1) and evaporation of the solvent as white solid (85\% yield). mp $158-159{ }^{\circ} \mathrm{C}$; IR (film) $v: 1689 \mathrm{~cm}^{-1}$; ${ }^{1} \mathrm{H}$ NMR (acetone-d6): $\delta=8.84\left(1 \mathrm{H}, \mathrm{s}, \mathrm{H}-5^{\prime}\right), 7.79(2 \mathrm{H}, \mathrm{d}, J 8.8 \mathrm{~Hz}$, H-2"), $7.71(1 \mathrm{H}, \mathrm{d}, J 16 \mathrm{~Hz}, \mathrm{H}-3), 7.70(2 \mathrm{H}, \mathrm{d}, J 7.2 \mathrm{~Hz}, \mathrm{H}-2$ "' and H-6"'), 7.55 (2H, t, J 7.2 Hz, H-3"' and H-5"'), 7.48 (1H, t, J 7.2 Hz, H-4"”), 7.01 (2H, d, J $8.8 \mathrm{~Hz}, \mathrm{H}-3$ "), 6.44 (1H, d, J $16 \mathrm{~Hz}, \mathrm{H}-2), 4.19$ $\left(2 \mathrm{H}, \mathrm{q}, J 7.2 \mathrm{~Hz}, \mathrm{OCH}_{2} \mathrm{CH}_{3}\right), 1.27\left(3 \mathrm{H}, \mathrm{t}, J 7.2 \mathrm{~Hz}, \mathrm{OCH}_{2} \mathrm{CH}_{3}\right) ;{ }^{13} \mathrm{C}$ NMR (acetone-d6): 166.4 (C-1), 156.7 (C-4"), 152.2 (C-3'), 134.8 (C-4'), 132.9 (C-1"), 132.4 (C-1"'), 128.6 (C-3"' and C-5"'), 128.5 (C-2"' and C-6"'), 128.3 (C-4"'), 127.3 (C-3), 120.6 (C-2"), 117.1 (C-5'), 116.8 (C-2), 115.9 (C-3"), $59.68\left(\mathrm{OCH}_{2} \mathrm{CH}_{3}\right), 13.74\left(\mathrm{OCH}_{2}-\right.$ $\left.\mathrm{CH}_{3}\right)$; MS: $335.22\left(\mathrm{M}+\mathrm{H}^{+}\right)$. Anal. Calcd for $\mathrm{C}_{20} \mathrm{H}_{18} \mathrm{~N}_{2} \mathrm{O}_{3}$ : C, 71.84; H, 5.43; N, 8.38. Found: C, 71.99; H, 5.52; N 8.21.

4.2.10.2. (E)-ethyl 3-(1'-(4"-hydroxyphenyl)-3'-(3"'-hydroxyphenyl)-1'H-pyrazol-4'-yl) acrylate (10b). According to the general procedure, deprotected ester 10b was obtained from ester $\mathbf{9 b}$ after purification by flash column chromatography (Hex/EtOAc, $1: 1$ ) and evaporation of the solvent as yellow solid (85\% yield). mp 190-191 ${ }^{\circ} \mathrm{C}$; IR (film) $v$ : $1692 \mathrm{~cm}^{-1}$; ${ }^{1} \mathrm{H}$ NMR (acetone-d6): $\delta=8.82(1 \mathrm{H}, \mathrm{s}, \mathrm{H}-5$ '), 7.78 (2H, d, $J 8.8 \mathrm{~Hz}, \mathrm{H}-2$ "), $7.73(1 \mathrm{H}, \mathrm{d}, J$ $16 \mathrm{~Hz}, \mathrm{H}-3), 7.36(1 \mathrm{H}, \mathrm{t}, J 8.0 \mathrm{~Hz}, \mathrm{H}-5$ "'), $7.20(1 \mathrm{H}, \mathrm{d}, J 1.6 \mathrm{~Hz}, \mathrm{H}-$ 2”'), 7.16 (1H, d, J $8.0 \mathrm{~Hz}, \mathrm{H}-4$ "'), 7.00 (2H, d, J $8.8 \mathrm{~Hz}, \mathrm{H}-3$ "), 6.95
(1H, dd, J $8.0 \mathrm{~Hz} J 1.6 \mathrm{~Hz}, \mathrm{H}-6$ "'), 6.44 (1H, d, J $16 \mathrm{~Hz}, \mathrm{H}-2), 4.19$ $\left(2 \mathrm{H}, \mathrm{q}, J 7.2 \mathrm{~Hz}, \mathrm{OCH}_{2} \mathrm{CH}_{3}\right), 1.27\left(3 \mathrm{H}, \mathrm{t}, J 7.2 \mathrm{~Hz}, \mathrm{OCH}_{2} \mathrm{CH}_{3}\right) ;{ }^{13} \mathrm{C}$ NMR (acetone-d6): 166.5 (C-1), 157.7 (C-3"'), 156.7 (C-4"), 152.1 (C-3'), 136.2 (C-4'), 135.0 (C-1" and C-1'”), 129.7 (C-3), 127.2 (C5"'), 120.6 (C-5'and C-2"), 119.7 (C-6"'), 116.9 (C-4"'), 115.9 (C3"), 115.4 (C-2"'), 115.4 (C-2), $59.71\left(\mathrm{OCH}_{2} \mathrm{CH}_{3}\right), 13.78\left(\mathrm{OCH}_{2} \mathrm{CH}_{3}\right)$; MS: $351.02\left(\mathrm{M}+\mathrm{H}^{+}\right)$. Anal. Calcd for $\mathrm{C}_{20} \mathrm{H}_{18} \mathrm{~N}_{2} \mathrm{O}_{4}$ : C, 68.56; $\mathrm{H}, 5.18$; N, 8.00. Found: C, 68.75; H, 5.32; N 8.18.

4.2.10.3. (E)-ethyl 3-(1'-(4"-hydroxyphenyl)-3'-(4"'-hydroxyphenyl)-1'H-pyrazol-4'-yl) acrylate (10c). According to the general procedure, deprotected ester 10c was obtained from ester 9c after purification by flash column chromatography (Hex/EtOAc, $1: 1)$ and evaporation of the solvent as white solid (85\% yield). mp 248-249 ${ }^{\circ} \mathrm{C}$; IR (film) $v: 1693 \mathrm{~cm}^{-1} ;{ }^{1} \mathrm{H}$ NMR (DMSO): $\delta=9.00(1 \mathrm{H}$ s, H-5'), 7.67 (2H, d, J $8.4 \mathrm{~Hz}, \mathrm{H}-2$ "' and H-6"'), $7.54(1 \mathrm{H}, \mathrm{d}, J 16 \mathrm{~Hz}$, H-3), 7.41 (2H, d, J 8.0 Hz, H-2"), 6.93-6.90 (4H, m, H-3" H-3"' and H-5”'), $6.46(1 \mathrm{H}, \mathrm{d}, J 16 \mathrm{~Hz}, \mathrm{H}-2), 4.16\left(2 \mathrm{H}, \mathrm{q}, J 6.8 \mathrm{~Hz}, \mathrm{OCH}_{2} \mathrm{CH}_{3}\right)$ 1.24 (3H, t, J $\left.6.8 \mathrm{~Hz}, \mathrm{OCH}_{2} \mathrm{CH}_{3}\right) ;{ }^{13} \mathrm{C}$ NMR (DMSO): 167.0 (C-1), 158.3 (C-4"'), 156.9 (C-4"), 152.5 (C-3'), 135.6 (C-4'), 131.8 (C-1"), 130.1 (C-2"' and C-6"'), 128.4 (C-3), 123.9 (C-1"'), 120.8 (C-2"), 116.6 (C5'), 116.4 (C-2), 116.3 (C-3"' and C-5"), 116.1 (C-3"), 60.26 $\left(\mathrm{OCH}_{2} \mathrm{CH}_{3}\right)$, $14.68\left(\mathrm{OCH}_{2} \mathrm{CH}_{3}\right)$; MS: $351.10\left(\mathrm{M}+\mathrm{H}^{+}\right)$. Anal. Calcd for $\mathrm{C}_{20} \mathrm{H}_{18} \mathrm{~N}_{2} \mathrm{O}_{4}: \mathrm{C}$, 68.56; H, 5.18; N, 8.00. Found: C, 68.40; H, 5.31; N 7.88.

4.2.10.4. (E)-ethyl 3-(1'-(4"-hydroxyphenyl)-3'-(3"',4"'-dihydroxyphenyl)- 1'H-pyrazol-4'-yl) acrylate (10d). According to the general procedure, deprotected ester 10d was obtained from ester 9d after purification by flash column chromatography (EtOAc) and evaporation of the solvent as brown solid (85\% yield). mp 203$204{ }^{\circ} \mathrm{C}$; IR (film) $v: 1698 \mathrm{~cm}^{-1} ;{ }^{1} \mathrm{H}$ NMR (acetone-d6): $\delta=8.78$ (1H, s, H-5'), 7.76 (2H, d, J 9.2 Hz, H-2"),7.73 (1H, d, J $16 \mathrm{~Hz}, \mathrm{H}-3$ ), 7.21 (1H, d, J $2.0 \mathrm{~Hz}, \mathrm{H}-2$ "'), 7.04 (1H, dd, J $8.0 \mathrm{~Hz} J 2.0 \mathrm{~Hz}, \mathrm{H}-6$ "'), 6.99 (2H, d, J $9.2 \mathrm{~Hz}, \mathrm{H}-3$ "), 6.98 (1H, d, J $8.2 \mathrm{~Hz}, \mathrm{H}-5$ "”), 6.41 (1H, d, $J 16 \mathrm{~Hz}, \mathrm{H}-2), 4.19\left(2 \mathrm{H}, \mathrm{q}, J 7.2 \mathrm{~Hz}, \mathrm{OCH}_{2} \mathrm{CH}_{3}\right), 1.27(3 \mathrm{H}, \mathrm{t}, J 7.2 \mathrm{~Hz}$, $\left.\mathrm{OCH}_{2} \mathrm{CH}_{3}\right) ;{ }^{13} \mathrm{C}$ NMR (acetone-d6): 166.5 (C-1), 156.4 (C-4"), 152.4 (C-3'), 145.6 (C-3"'), 145.1 (C-4"'), 135.3 (C-4'), 132.5 (C-1"), 127.0 (C-3), 124.7 (C-5'), 120.5 (C-2" C-1"' and C-6"'), 116.5 (C-5"'), 115.8 (C-3"), 115.5 (C-2"'), 115.3 (C-2), $59.63\left(\mathrm{OCH}_{2} \mathrm{CH}_{3}\right), 13.75$ $\left(\mathrm{OCH}_{2} \mathrm{CH}_{3}\right)$; MS: $367.27\left(\mathrm{M}+\mathrm{H}^{+}\right)$. Anal. Calcd for $\mathrm{C}_{20} \mathrm{H}_{18} \mathrm{~N}_{2} \mathrm{O}_{5}$ : C, 65.57; H, 4.95; N, 7.65. Found: C, 65.75; H, 5.12; N 7.78.

4.2.10.5. (E)-ethyl 3-1'-(4"- hydroxyphenyl)-3'-(2"',5"'- dihydroxyphenyl)-1'H-pyrazol-4'-yl) acrylate (10e). According to the general procedure, deprotected ester $\mathbf{1 0 e}$ was obtained from ester $\mathbf{9 e}$ after purification by flash column chromatography (Hex/EtOAc, $1: 1$ ) and evaporation of the solvent as yellow solid (85\% yield). mp 236-237 ${ }^{\circ} \mathrm{C}$; IR (film) $v: 1696 \mathrm{~cm}^{-1} ;{ }^{1} \mathrm{H}$ NMR (DMSO): $\delta=8.96$ (1H, s, H-5'), 7.66 (2H, d, J 9.2 Hz, H-2"), 7.47 (1H, d, J $16 \mathrm{~Hz}, \mathrm{H}-3$ ), $6.91(2 \mathrm{H}, \mathrm{d}, J 8.8 \mathrm{~Hz}, \mathrm{H}-3$ "), $6.80(1 \mathrm{H}, \mathrm{d}, J 8.4 \mathrm{~Hz}, \mathrm{H}-3$ "”), $6.72(1 \mathrm{H}$, dd, J 8.4 Hz J $2.8 \mathrm{~Hz}, \mathrm{H}-4$ "'), 6.71 (1H, d, J $2.8 \mathrm{~Hz}, \mathrm{H}-6$ "'), 6.32 (1H, d, $J 16 \mathrm{~Hz}, \mathrm{H}-2), 4.13\left(2 \mathrm{H}, \mathrm{q}, J 7.2 \mathrm{~Hz}, \mathrm{OCH}_{2} \mathrm{CH}_{3}\right), 1.22(3 \mathrm{H}, \mathrm{t}, J 7.2 \mathrm{~Hz}$, $\left.\mathrm{OCH}_{2} \mathrm{CH}_{3}\right) ;{ }^{13} \mathrm{C}$ NMR (DMSO): 167.1 (C-1), 156.9 (C-4"), 150.8 (C-3'), 150.2 (C-5"'), 148.0 (C-2"'), 136.9 (C-4'), 131.9 (C-1"), 127.9 (C-3), 120.7 (C-2"), 119.9 (C-5'), 118.2 (C-4"'), 117.4 (C-3"”) 117.2 (C-6"), 117.1 (C-1"'), 116.3 (C-3"), 115.7 (C-2), $60.10\left(\mathrm{OCH}_{2} \mathrm{CH}_{3}\right)$, 14.67 $\left(\mathrm{OCH}_{2} \mathrm{CH}_{3}\right)$; MS: $367.29\left(\mathrm{M}+\mathrm{H}^{+}\right)$. Anal. Calcd for $\mathrm{C}_{20} \mathrm{H}_{18} \mathrm{~N}_{2} \mathrm{O}_{5}$ : C, 65.57; H, 4.95; N, 7.65. Found: C, 65.77; H, 5.10; N 7.78.

4.2.11. General procedure for the synthesis of acids 11a-e 4.2.11.1. Synthesis of (E)-3-(1'-(4'-methoxyphenyl)-3'-phenyl1'H-pyrazol-4'-yl) acrylic acid (11a). A solution of ester 9a $(0.90 \mathrm{~g}, 2.6 \mathrm{mmol})$ and $\mathrm{NaOH}(1.8 \mathrm{~mL}, 5 \mathrm{~N})$ in 1.3:1 EtOH-DMSO $(46 \mathrm{~mL})$, was stirred overnight at room temperature. After completion of the reaction, DEE was added and the water layer was extracted twice with $\mathrm{H}_{2} \mathrm{O}$. Next, the solution was acidified with 
$\mathrm{HCl}(1 \mathrm{~N})$ to $\mathrm{pH}=2$ to form a precipitate that was filtered off, washed with water and dried over $\mathrm{P}_{2} \mathrm{O}_{5}$ atmosphere to provide acid $11 \mathrm{a}$ as white solid (90\% yield). mp $205-206{ }^{\circ} \mathrm{C}$; IR (film) $v$ : $1693 \mathrm{~cm}^{-1}{ }^{1} \mathrm{H}$ NMR (DMSO): $\delta=9.11\left(1 \mathrm{H}, \mathrm{s}, \mathrm{H}-5^{\prime}\right), 7.84(2 \mathrm{H}, \mathrm{d}, J$ $7.2 \mathrm{~Hz}, \mathrm{H}-2$ "' and H-6"'), 7.62-7.51 (6H, m, H-3, H-2", H-3"', H-4"' and $\mathrm{H}-5$ "'), 7.12 (2H, d, J 7.6 Hz, H-3"), 6.44 (1H, d, J $16 \mathrm{~Hz}, \mathrm{H}-2)$, $3.82\left(3 \mathrm{H}, \mathrm{s}, \mathrm{OCH}_{3}\right) ;{ }^{13} \mathrm{C}$ NMR (DMSO): 168.2 (C-1), 158.7 (C-4"), 152.2 (C-3'), 134.7 (C-3), 133.1 (C-4'), 132.6 (C-1"), 129.3 (C-2”' and (C-6"'), 129.0 (C-1"'), 128.8 (C-3"' and C-5"'), 128.6 (C-4"'), 120.7 (C-2"), 118.6 (C-5'), 117.1 (C-2), 115.2 (C-3"), $55.95\left(\mathrm{OCH}_{3}\right)$; MS: $321.23\left(\mathrm{M}+\mathrm{H}^{+}\right)$. Anal. Calcd for $\mathrm{C}_{19} \mathrm{H}_{16} \mathrm{~N}_{2} \mathrm{O}_{3}$ : C, 71.24; $\mathrm{H}$, 5.03; N, 8.74. Found: C, 71.07; H, 5.12; N 8.88.

4.2.11.2. (E)-3-(1'-(4"-methoxyphenyl)-3'-(3"'-methoxyphenyl)1'H-pyrazol-4'-yl) acrylic acid (11b). According to the general procedure, acid 11b was obtained from ester $\mathbf{9 b}$ as white solid (90\% yield). mp $168-169{ }^{\circ} \mathrm{C}$; IR (film) $v: 1685 \mathrm{~cm}^{-1} ;{ }^{1} \mathrm{H}$ NMR $\left(\mathrm{CDCl}_{3}\right): \delta=8.20\left(1 \mathrm{H}, \mathrm{s}, \mathrm{H}-5^{\prime}\right), 7.87(1 \mathrm{H}, \mathrm{d}, J 16 \mathrm{~Hz}, \mathrm{H}-3), 7.70(2 \mathrm{H}$, d, J $8.8 \mathrm{~Hz}, \mathrm{H}-2$ "), 7.43 (1H, t, J $8.0 \mathrm{~Hz}, \mathrm{H}-5$ "'), 7.29 (2H, m, H-2"' and H-6"'), 7.02 (3H, m, H-3" and H-4"'), $6.28(1 \mathrm{H}, \mathrm{d}, J 16 \mathrm{~Hz}, \mathrm{H}-$ 2), $3.90\left(3 \mathrm{H}, \mathrm{s}, \mathrm{C} 3\right.$ "'- $\left.-\mathrm{OCH}_{3}\right), 3.88\left(3 \mathrm{H}, \mathrm{s}, \mathrm{C} 4\right.$ "'- $\left.\mathrm{OCH}_{3}\right) ;{ }^{13} \mathrm{C}$ NMR $\left(\mathrm{CDCl}_{3}\right)$ : 168.1 (C-1), 159.9 (C-3"”), 158.6 (C-4"), 152.2 (C-3'), 134.8 (C-4'), 133.5 (C-1"), 133.1 (C-1"'), 131.7 (C-3), 127.1 (C-5"'), 122.3 (C-5'), 120.5 (C-2"), 117.8 (C-4"' and C-6"'), 115.0 (C-3" and C-2"'), 114.0 (C-2), $55.93\left(\mathrm{C}^{\prime \prime}-\mathrm{OCH}_{3}\right), 55.66\left(\mathrm{C}^{\prime \prime}\right.$ '- $\left.-\mathrm{OCH}_{3}\right)$; MS: $351.02\left(\mathrm{M}+\mathrm{H}^{+}\right)$. Anal. Calcd for $\mathrm{C}_{20} \mathrm{H}_{18} \mathrm{~N}_{2} \mathrm{O}_{4}$ : C, 68.56; $\mathrm{H}, 5.18 ; \mathrm{N}$, 8.00. Found: C, 68.72; H, 5.11; N 8.08.

4.2.11.3. (E)-3-(1'-(4"-methoxyphenyl)-3'-(4"'-methoxyphenyl)1'H-pyrazol-4'-yl) acrylic acid (11c). According to the general procedure, acid 11c was obtained from ester 9c as white solid (90\% yield). mp $210-211^{\circ} \mathrm{C}$; IR (film) $v$ : $1693 \mathrm{~cm}^{-1}$; ${ }^{\mathbf{1}} \mathbf{H}$ NMR (DMSO): $\delta=9.02\left(1 \mathrm{H}, \mathrm{s}, \mathrm{H}-5^{\prime}\right), 7.78(2 \mathrm{H}, \mathrm{d}, J 8.8 \mathrm{~Hz}, \mathrm{H}-2$ '” and $\mathrm{H}-$ 6"'), 7.50 (2H, d, J $8.4 \mathrm{~Hz}, \mathrm{H}-2$ "), 7.47 (1H, d, J $16 \mathrm{~Hz}, \mathrm{H}-3), 7.06$ (4H, m, H-3", H-3"' and H-5"'), $6.36(1 \mathrm{H}, \mathrm{d}, J 16 \mathrm{~Hz}, \mathrm{H}-2), 3.78$ $\left(3 \mathrm{H}, \mathrm{s}, \mathrm{C} 4\right.$ "'- $\left.\mathrm{OCH}_{3}\right), 3.77\left(3 \mathrm{H}, \mathrm{s}, \mathrm{C} 4\right.$ "'-OCH $\left.\mathrm{OCH}_{3}\right) ;{ }^{13} \mathrm{C}$ NMR (DMSO): 168.3 (C-1), 160.0 (C-4"”), 158.7 (C-4”), 152.1 (C-3'), 134.9 (C-4'), 133.1 (C-1"), 130.1 (C-2"' and C-6"'), 128.4 (C-3), 124.9 (C-1"'), 120.6 (C-2"), 118.1 (C-5'), 117.0 (C-2), 115.1 (C-3"' and C-5"'), 114.7 (C-3"), $55.92\left(\mathrm{C}^{\prime \prime}-\mathrm{OCH}_{3}\right), 55.68\left(\mathrm{C}^{\prime \prime \prime}-\mathrm{OCH}_{3}\right)$; MS: 351.15 $\left(\mathrm{M}+\mathrm{H}^{+}\right)$. Anal. Calcd for $\mathrm{C}_{20} \mathrm{H}_{18} \mathrm{~N}_{2} \mathrm{O}_{4}$ : C, 68.56; H, 5.18; N, 8.00. Found: C, 68.44; H, 5.09; N 7.89.

4.2.11.4. (E)-3-(1'-(4"-methoxyphenyl)-3'-(3"',4"'-dimethoxyphenyl)-1'H-pyrazol-4'-yl) acrylic acid (11d). According to the general procedure, acid 11d was obtained from ester 9d as white solid (90\% yield). mp $173-174{ }^{\circ} \mathrm{C}$; IR (film) $v: 1694 \mathrm{~cm}^{-1} ;{ }^{\mathbf{1}} \mathbf{H}$ NMR $\left(\mathrm{CDCl}_{3}\right): \delta=8.18\left(1 \mathrm{H}, \mathrm{s}, \mathrm{H}-5^{\prime}\right), 7.85(1 \mathrm{H}, \mathrm{d}, J 16 \mathrm{~Hz}, \mathrm{H}-3)$, $7.69(2 \mathrm{H}, \mathrm{d}, J 8.0 \mathrm{~Hz}, \mathrm{H}-2$ "), $7.25(1 \mathrm{H}, \mathrm{s}, \mathrm{H}-2$ "'), $7.20(1 \mathrm{H}, \mathrm{d}, J$ $8.0 \mathrm{~Hz}, \mathrm{H}-6$ "'), 7.02-6.99 (3H, m, H-3" and H-5"'), $6.27(1 \mathrm{H}, \mathrm{d}, J$ $16 \mathrm{~Hz}, \mathrm{H}-2), 3.97$ (3H, s, C3'"-OCH $), 3.96\left(3 \mathrm{H}, \mathrm{s}, \mathrm{C} 4\right.$ '"'-OCH $\left.\mathrm{OCH}_{3}\right), 3.88$ (3H, s, C4"- $\left.\mathrm{OCH}_{3}\right) ;{ }^{13} \mathrm{C}$ NMR $\left(\mathrm{CDCl}_{3}\right): 167.4(\mathrm{C}-1), 158.6$ (C-4"), 152.7 (C-3'), 149.7 (C-3'”), 149.3 (C-4"'), 135.0 (C-4'), 132.8 (C1"), 126.1 (C-1"'), 122.8 (C-3), 121.1 (C-5'), 121.0 (C-2"), 120.9 (C-6"”), 118.4 (C-5"'), 115.0 (C-3"), 112.8 (C-2"'), 112.1 (C-2), $56.21\left(\mathrm{C}^{\prime \prime \prime}-\mathrm{OCH}_{3}\right.$ and $\left.\mathrm{C}^{\prime \prime \prime}-\mathrm{OCH}_{3}\right), 55.69\left(\mathrm{C}^{\prime} "-\mathrm{OCH}_{3}\right)$; MS: 381.31 $\left(\mathrm{M}+\mathrm{H}^{+}\right)$. Anal. Calcd for $\mathrm{C}_{21} \mathrm{H}_{20} \mathrm{~N}_{2} \mathrm{O}_{5}$ : C, 66.31; $\mathrm{H}, 5.30 ; \mathrm{N}, 7.36$. Found: C, 66.39; H, 5.23; N 7.42.

4.2.11.5. (E)-3-1'-(4"-methoxyphenyl)-3'-(2"',5"'-dimethoxyphenyl)-1'H-pyrazol-4'-yl) acrylic acid (11e). According to the general procedure, acid 11e was obtained from ester 9e as white solid (90\% yield). mp $187-188{ }^{\circ} \mathrm{C}$; IR (film) $v$ : $1685 \mathrm{~cm}^{-1} ;{ }^{\mathbf{1}} \mathbf{H}$ NMR (DMSO): $\delta=9.01$ (1H, s, H-5'), 7.80 (2H, d, J $8.8 \mathrm{~Hz}, \mathrm{H}-2$ "), $7.23(1 \mathrm{H}, \mathrm{d}, J 16 \mathrm{~Hz}, \mathrm{H}-3), 7.12(1 \mathrm{H}, \mathrm{d}, J 8.8 \mathrm{~Hz}, \mathrm{H}-3$ ”’), $7.10(2 \mathrm{H}$, d, J $8.8 \mathrm{~Hz}, \mathrm{H}-3$ "), 7.05 (1H, dd, J $8.8 \mathrm{HzJ} 2.8 \mathrm{~Hz}, \mathrm{H}-4$ "'), 6.94 (1H, d, J $2.8 \mathrm{~Hz}, \mathrm{H}-6$ "'), 6.20 (1H, d, J $16 \mathrm{~Hz}, \mathrm{H}-2), 3.82$ (3H, s, C5”'$\left.\mathrm{OCH}_{3}\right), 3.76\left(3 \mathrm{H}, \mathrm{s}, \mathrm{C} 2\right.$ '"- $\left.\mathrm{OCH}_{3}\right), 3.70\left(3 \mathrm{H}, \mathrm{s}, \mathrm{C}^{\prime}\right.$ "'-OCH $\left.\mathrm{OCH}_{3}\right) ;{ }^{13} \mathrm{C}$ NMR (DMSO): 168.3 (C-1), 158.5 (C-4"), 153.6 (C-3'), 151.4 (C-5”'), 150.2 (C-2"'), 135.7 (C-4'), 133.2 (C-1"), 127.9 (C-3), 122.4 (C-5'), 120.6 (C-2"), 118.6 (C-1"'), 117.0 (C-3"' and C-4"'), 115.7 (C-6"'), 115.1 (C-3"), 113.5 (C-2), $56.40\left(\mathrm{C}^{\prime \prime}-\mathrm{OCH}_{3}\right), 55.86\left(\mathrm{C}^{\prime \prime \prime}-\mathrm{OCH}_{3}\right.$ and $\mathrm{C}^{\prime}$ '- $\left.-\mathrm{OCH}_{3}\right)$; MS: $381.30\left(\mathrm{M}+\mathrm{H}^{+}\right)$. Anal. Calcd for $\mathrm{C}_{21} \mathrm{H}_{20} \mathrm{~N}_{2} \mathrm{O}_{5}$ : C, 66.31; H, 5.30; N, 7.36. Found: C, 66.44; H, 5.20; N 7.49.

4.2.12. General procedure for the demethylation of acids 11a-e 4.2.12.1. Synthesis of (E)-3-(1'-(4"'-hydroxyphenyl)-3'-phenyl1'H-pyrazol-4'-yl) acrylic acid (12a). To a stirred solution of the protected acid 11a $(0.20 \mathrm{~g}, 0.62 \mathrm{mmol})$ in $\mathrm{CH}_{2} \mathrm{Cl}_{2}(19 \mathrm{~mL})$ at $-78{ }^{\circ} \mathrm{C}$, $\mathrm{BBr}_{3}$ (3.1 mmol, $1.0 \mathrm{M}$ in $\mathrm{CH}_{2} \mathrm{Cl}_{2}$, 5 equiv per bond, $3.1 \mathrm{~mL}$ ) was added dropwise. The reaction was kept at $-78^{\circ} \mathrm{C}$ for $1 \mathrm{~h}$ and then for $16 \mathrm{~h}$ at room temperature. The solution was cooled at $0{ }^{\circ} \mathrm{C}$, neutralized with $\mathrm{MeOH}$ and then $\mathrm{HCl} 1 \mathrm{~N}$ was added. The organic phase was extracted twice with EtOAc. The combined organic extracts were washed with water, brine, dried with $\mathrm{Na}_{2} \mathrm{SO}_{4}$, filtered and evaporated. The formatting precipitate was filtered off, washed with DEE and dried over $\mathrm{P}_{2} \mathrm{O}_{5}$ atmosphere to provide the deprotected acid 12a as white solid ( $85 \%$ yield). mp $190-191{ }^{\circ} \mathrm{C}$; IR (film) $v: 1693 \mathrm{~cm}^{-1}$; ${ }^{1} \mathbf{H}$ NMR (DMSO): $\delta=9.03(1 \mathrm{H}, \mathrm{s}, \mathrm{H}-5$ '), $7.71(2 \mathrm{H}$, d, J $8.8 \mathrm{~Hz}, \mathrm{H}-2$ "), 7.61 (2H, d, J 7.2 Hz, H-2"' and H-6"'), 7.54 (2H, t, J $7.2 \mathrm{~Hz}, \mathrm{H}-3$ "' and H-5"'), $7.52(1 \mathrm{H}, \mathrm{d}, J 16 \mathrm{~Hz}, \mathrm{H}-3), 7.47(1 \mathrm{H}, 7$, J $7.2 \mathrm{~Hz}, \mathrm{H}-4$ "'), 6.92 (2H, d, J $8.8 \mathrm{~Hz}, \mathrm{H}-3$ "), 6.41 (1H, d, J $16 \mathrm{~Hz}$, $\mathrm{H}-2$ ); ${ }^{13}$ C NMR (DMSO): 168.2 (C-1), 157.0 (C-4"), 152.0 (C-3'), 134.8 (C-3), 132.7 (C-4'), 131.9 (C-1"), 129.3 (C-2"' and C-6"'), 128.9 (C-1"'), 128.8 (C-3"' and C-5"'), 128.5 (C-4"'), 121.0 (C-2"), 118.4 (C-5'), 116.8 (C-2), 116.4 (C-3"); MS: $307.23\left(\mathrm{M}+\mathrm{H}^{+}\right)$. Anal. Calcd for $\mathrm{C}_{18} \mathrm{H}_{14} \mathrm{~N}_{2} \mathrm{O}_{3}$ : C, 70.58; $\mathrm{H}, 4.61 ; \mathrm{N}, 9.15$. Found: C, 70.44; $\mathrm{H}, 4.50$; N 9.29.

4.2.12.2. (E)-3-(1'-(4"-hydroxyphenyl)-3'-(3"'-hydroxyphenyl)1'H-pyrazol-4'-yl) acrylic acid (12b). According to the general procedure, deprotected acid 12b was obtained from acid 11b as white solid (85\% yield). $\mathrm{mp} 246-247^{\circ} \mathrm{C}$; IR (film) $v: 1682 \mathrm{~cm}^{-1}$; ${ }^{1}$ H NMR (acetone-d6): $\delta=8.83\left(1 \mathrm{H}, \mathrm{s}, \mathrm{H}-5^{\prime}\right), 7.79(2 \mathrm{H}, \mathrm{d}, J 8.8 \mathrm{~Hz}$, H-2"), 7.76 (1H, d, J 16 Hz, H-3), 7.37 (1H, t, J 7.6 Hz, H-5"), 7.21 (1H, s, H-2"'), 7.17 (1H, d, J 7.6 Hz, H-4"'), $7.01(2 \mathrm{H}, \mathrm{d}, J 8.8 \mathrm{~Hz}, \mathrm{H}-$ 3"), 6.95 (1H, dd, J $7.6 \mathrm{~Hz} J 1.6 \mathrm{~Hz}, \mathrm{H}-6$ ”"), 6.43 (1H, d, J $16 \mathrm{~Hz}, \mathrm{H}-$ 2); ${ }^{13}$ C NMR (acetone-d6): 167.2 (C-1), 157.6 (C-3"'), 156.6 (C4"), 152.1 (C-3'), 135.4 (C-4'), 134.1 (C-1"), 132.5 (C-1'”), 129.7 (C-3), 127.2 (C-5"'), 120.6 (C-2" and C-6"'), 119.8 (C-2), 117.0 (C5'), 116.8 (C-4"'), 115.9 (C-3"), 115.4 (C-2"'); MS: $323.96\left(\mathrm{M}+\mathrm{H}^{+}\right)$. Anal. Calcd for $\mathrm{C}_{18} \mathrm{H}_{14} \mathrm{~N}_{2} \mathrm{O}_{4}$ : C, 67.07; H, 4.38; N, 8.69. Found: C, $66.91 ; \mathrm{H}, 4.50 ; \mathrm{N} 8.55$.

4.2.12.3. (E)-3-(1'-(4"'-hydroxyphenyl)-3'-(4"'-hydroxyphenyl)1'H-pyrazol-4'-yl) acrylic acid (12c). According to the general procedure, deprotected acid 12c was obtained from acid 11c as white solid (85\% yield). mp 202-203 ${ }^{\circ} \mathrm{C}$; IR (film) $v: 1682 \mathrm{~cm}^{-1}$; ${ }^{1}$ H NMR (acetone-d6): $\delta=8.78(1 \mathrm{H}, \mathrm{s}, \mathrm{H}-5$ ') $7.78(2 \mathrm{H}, \mathrm{d}, J 8.8 \mathrm{~Hz}$, H-2"' and H-6"'), $7.72(1 \mathrm{H}, \mathrm{d}, J 16 \mathrm{~Hz}, \mathrm{H}-3), 7.55(2 \mathrm{H}, \mathrm{d}, J 8.4 \mathrm{~Hz}$, H-2"), 7.01 (2H, d, J $8.4 \mathrm{~Hz}, \mathrm{H}-3$ "), 7.00 (2H, d, J $8.8 \mathrm{~Hz}, \mathrm{H}-3$ "' and H-5”'), 6.40 (1H, d, J $16 \mathrm{~Hz}, \mathrm{H}-2) ;{ }^{13} \mathrm{C}$ NMR (acetone-d6): 167.2 (C-1), 157.9 (C-4"'), 156.5 (C-4"), 152.4 (C-3'), 135.6 (C-4'), 132.5 (C-1"), 129.9 (C-2"' and C-6"'), 127.0 (C-3), 124.1 (C-1"'), 120.5 (C-2"), 116.6 (C-5'), 116.5 (C-2), 115.8 (C-3"” and C-5"'), 115.5 (C3"); MS: $323.14\left(\mathrm{M}+\mathrm{H}^{+}\right)$. Anal. Calcd for $\mathrm{C}_{18} \mathrm{H}_{14} \mathrm{~N}_{2} \mathrm{O}_{4}$ : C, 67.07; $\mathrm{H}$, 4.38; N, 8.69. Found: C, 66.93; H, 4.31; N 8.60.

4.2.12.4. (E)-3-(1'-(4"-hydroxyphenyl)-3'-(3"',4"'-dihydroxyphenyl)-1'H-pyrazol-4'-yl) acrylic acid (12d). According to the general procedure, deprotected acid 12d was obtained from acid 11d as white solid ( $85 \%$ yield). $\mathrm{mp} 237-238^{\circ} \mathrm{C}$; IR (film) $v$ : 
$1710 \mathrm{~cm}^{-1} ;{ }^{\mathbf{1}} \mathbf{H}$ NMR (acetone-d6): $\delta=8.78\left(1 \mathrm{H}, \mathrm{s}, \mathrm{H}-5^{\prime}\right), 7.77(2 \mathrm{H}$, d, $J 8.8 \mathrm{~Hz}, \mathrm{H}-2$ "), $7.75(1 \mathrm{H}, \mathrm{d}, J 16 \mathrm{~Hz}, \mathrm{H}-3), 7.22(1 \mathrm{H}, \mathrm{d}, J 2.0 \mathrm{~Hz}$, H-2"'), 7.05 (1H, dd, J $8.0 \mathrm{~Hz} J 2.0 \mathrm{~Hz}, \mathrm{H}-6$ '”), 7.00 (2H, d, J $8.8 \mathrm{~Hz}$, H-3"), 6.98 (1H, d, J $8.0 \mathrm{~Hz}, \mathrm{H}-5$ "'), 6.40 (1H, d, J $16 \mathrm{~Hz}, \mathrm{H}-2) ;{ }^{13} \mathrm{C}$ NMR (acetone-d6): 167.2 (C-1), 156.5 (C-4"), 152.4 (C-3'), 145.7 (C-3"'), 145.1 (C-4"'), 135.7 (C-4'), 132.5 (C-1"), 127.0 (C-1"'), 124.7 (C-3), 120.4 (C-5' and C-2"), 116.6 (C-6"'), 116.5 (C-2), 115.8 (C-3"), 115.6 (C-2"'), 115.4 (C-5”'); MS: $339.23\left(\mathrm{M}+\mathrm{H}^{+}\right)$. Anal. Calcd for $\mathrm{C}_{18} \mathrm{H}_{14} \mathrm{~N}_{2} \mathrm{O}_{5}$ : C, 63.90; H, 4.17; N, 8.28. Found: C, 64.03; H, 4.25 ; N 8.40 .

4.2.12.5. (E)-3-1'-(4"'-hydroxyphenyl)-3'-(2"',5"'-dihydroxyphenyl)-1'H-pyrazol-4'-yl) acrylic acid (12e). According to the general procedure, deprotected acid 12e was obtained from acid 11e as white solid ( $85 \%$ yield). $\mathrm{mp} 258-259^{\circ} \mathrm{C}$; IR (film) $v$ : $1698 \mathrm{~cm}^{-1}$; ${ }^{1} \mathbf{H}$ NMR (DMSO): $\delta=8.93(1 \mathrm{H}, \mathrm{s}, \mathrm{H}-5$ '), $7.66(2 \mathrm{H}, \mathrm{d}, J$ $8.8 \mathrm{~Hz}, \mathrm{H}-2$ "), 7.42 (1H, d, J $16 \mathrm{~Hz}, \mathrm{H}-3), 6.75$ (2H, d, J $8.8 \mathrm{~Hz}, \mathrm{H}-$ 3"), 6.80 (1H, d, J $8.4 \mathrm{~Hz}, \mathrm{H}-3$ '”), $6.72(1 \mathrm{H}, \mathrm{dd}, J 8.4 \mathrm{HzJ} 3.2 \mathrm{~Hz}, \mathrm{H}-$ 4"'), 6.71 (1H, d, J $3.2 \mathrm{~Hz}, \mathrm{H}-6$ "'), $6.24(1 \mathrm{H}, \mathrm{d}, J 16 \mathrm{~Hz}, \mathrm{H}-2) ;{ }^{13} \mathrm{C}$ NMR (DMSO): 168.5 (C-1), 156.8 (C-4"), 150.7 (C-3'), 150.2 (C5”'), 148.0 (C-2"'), 136.4 (C-4'), 132.0 (C-1"), 127.6 (C-3), 120.7 (C-2"), 119.9 (C-5'), 118.3 (C-2), 117.4 (C-6"'), 117.1 (C-3"' and C4"'), 116.9 (C-1"”), 116.3 (C-3"); MS: $339.22\left(\mathrm{M}+\mathrm{H}^{+}\right)$. Anal. Calcd for $\mathrm{C}_{18} \mathrm{H}_{14} \mathrm{~N}_{2} \mathrm{O}_{5}$ : C, 63.90; $\mathrm{H}, 4.17 ; \mathrm{N}, 8.28$. Found: C, 64.11; $\mathrm{H}$, $4.27 ; \mathrm{N} 8.44$.

\subsection{Biological assays}

\subsubsection{Cell cultures}

Mouse aortic endothelial cells (MAEC) and bovine aortic endothelial cells (BAEC) were kindly provided by Prof. M. Presta (Brescia, Italy). Human cervical carcinoma (Hela) and human breast carcinoma (MCF-7) cells were obtained from the American Type Culture Collection (ATCC, Middlesex, UK). The cells were grown in Dulbecco's modified minimum essential medium (DMEM, Life Technologies, Inc., Rockville, MD) supplemented with $10 \mathrm{mM}$ Hepes (Life Technologies, Inc., Rockville, MD) and 10\% fetal bovine serum (FBS, Harlan Sera-Lab Ltd., Loughborough, UK).

\subsubsection{Cell Proliferation assays}

Cells (MAEC, BAEC, Hela or MCF-7) were seeded in 48-well plates at 10,000 cells per $\mathrm{cm}^{2}$. After $16 \mathrm{~h}$, the cells were incubated in fresh medium in the presence of the test compounds, as indicated in the Results section. On day 5, cells were trypsinized and counted by a Coulter counter (Analis, Belgium).

\subsubsection{Cell migration assay}

Wounds were created in confluent MAE cell monolayers with a $1.0-\mathrm{mm}$ wide micropipette tip. Then, cells were incubated in fresh medium containing 10\% FCS in the presence of the test compounds. After $8 \mathrm{~h}$, the wounds were photographed, and endothelial cells invading the wound were quantified by computerized analysis of the digitalized images.

\subsubsection{Chorioallantoic membrane (CAM) assay in fertilized chicken eggs}

The in vivo CAM angiogenesis model was performed as described with slight modifications. ${ }^{19}$ Fertilized eggs were incubated for 3 days at $37^{\circ} \mathrm{C}$ when $3 \mathrm{ml}$ of albumen was removed (to detach the shell from the developing (AM) and a window was opened on the eggshell exposing the CAM. The window was covered with cel- lophane tape and the eggs were returned to the incubator until day 9 when the compounds were applied. The compounds were placed on sterile plastic discs ( $\varnothing 8 \mathrm{~mm}$ ), which were allowed to dry under sterile conditions. A solution of cortisone acetate $(100 \mu \mathrm{g} / \mathrm{disc}$, Sigma, St. Louis, MO) was added to all discs in order to prevent an inflammatory response. A loaded and dried control disc was placed on the CAM approximately $1 \mathrm{~cm}$ away from the disc containing the test compound(s). Next, the windows were covered and the eggs further incubated until day 11 when the area around the discs was cut-off and photographed. Next 2 concentric circles were positioned on the digitalized pictures and all vessels intersecting these circles were counted. A two-tailed paired Student's $t$-test was used to assess the significance of the obtained results.

\section{Acknowledgments}

The authors wish to thank Mrs. Eef Meyen for dedicated technical help. This research was supported by grants from the Flemish FWO (Krediet nr. G. 0486.08), the Concerted Actions (GOA nr. 05/19), the Centers of Excellence (Krediet nr. 05/15) (to S.L.) and COST action CM 602 (Angiokem, to S.L. and S.H.).

\section{References and notes}

1. Folkman, J. N. Eng. J. Med. 1971, 285, 1182.

2. Liekens, S.; De Clercq, E.; Neyts Biochem. Pharmacol. 2001, 61, 253.

3. Carmeliet, P. Nature 2005, 438, 932.

4. Folkman, J. Nat. Rev. Drug Disc. 2007, 6, 273.

5. Folkman, J. Nat. Med. 1995, 1, 27.

6. Zheng, L. W.; Wu, L. L.; Zhao, B. X.; Dong, W. L.; Miao, J. Y. Bioorg. Med. Chem. 2008, 17, 1957.

7. (a) Hennequin, L. F.: Thomas, A. P.; Johnstone, C.; Stokes, E. S. E.; Plé, P. A. Lohmann, J. J. M.; Ogilvie, D. J.; Dukes, M.; Wedge, S. R.; Curwen, J. O.; Kendrew, J.; Lambert-van der Brempt, C. J. Med. Chem. 1999, 42, 5369; (b) Kallander, L. S.; Lu, Q.; Chen, W.; Tomaszek, T.; Yang, G.; Tew, D.; Meek, T. D.; Hofmann, G. A.; Schulz-Pritchard, C. K.; Smith, W. W.; Janson, C. A.; Ryan, M. D.; Zhang, G. F.; Johanson, K. O.; Kirkpatrick, R. B.; Ho, T. F.; Fisher, P. W.; Mattern, M. R.; Johnson, R. K.; Hansbury, M. J.; Winkler, J. D.; Ward, K. W.; Veber, D. F.; Thompson, S. K. J. Med. Chem. 2005, 48, 5644; (c) Carraro, F.; Naldini, A.; Pucci, A.; Locatelli, G. A.; Maga, G.; Schenone, S.; Bruno, O.; Ranise, A.; Bondavalli, F.; Brullo, C.; Fossa, P.; Menozzi, G.; Mosti, L.; Modugno, M.; Tintori, C.; Manetti, F.; Botta, M. J. Med. Chem. 2006, 49, 1549; (d) Semones, M.; Feng, Y.; Johnson, N.; Adams, J. L.; Winkler, J.; Hansbury, M. Bioorg. Med. Chem. 2007, 17, 4756.

8. De Luca, L.; Giacomelli, G.; Masala, S.; Porcheddu, A. Synlett 2004, 2299.

9. Chinchilla, R.; Dodsworth, D. J.; Nájera, C.; Soriano, J. M. Tetrahedron Lett. 2000, 41, 2463.

10. Christodoulou, M. S.; Kasiotis, K. M.; Fokialakis, N.; Tellitu, I.; Haroutounian, S. A. Tetrahedron Lett. 2008, 49, 7100.

11. Kasiotis, K. M.; Fokialakis, N.; Haroutounian, S. A. Synthesis 2006, 11, 1791.

12. (a) A. Varvoglis, Hypervalent Iodine in Organic Synthesis, Academic Press, London, 1997.; (b) Zhdankin, V. V.; Stang, P. J. Chem. Rev. 2002, 102, 2523 2584; (c) Stang, P. J. J. Org. Chem. 2003, 68, 2997-3008; (d) Wirth, T. Top. Curr. Chem. 2003, 224, 1-264; (e) Tohma, H.; Kita, Y. Adv. Synth. Catal. 2004, 346, 111-124; (f) Moriarty, R. M. J. Org. Chem. 2005, 70, 2893-2903; (g) Wirth, T. Angew. Chem., Int. Ed. 2005, 44, 3656-3665.

13. Tufan, A. C.; Satiroglu-Tufan, N. L. Curr. Cancer Drug Targets 2005, 5, 249-266.

14. Fong, T. A.; Shawver, L. K.; Sun, L.; Tang, C.; App, H.; Powell, T. J.; Kim, Y. H. Schreck, R.; Wang, X.; Risau, W.; Ullrich, A.; Hirth, K. P.; McMahon, G. Cancer Res. 1999, 59, 99.

15. Grgic, I.; Eichler, I.; Heinau, P.; Si, H.; Brakemeier, S.; Hoyer, J.; Köhler, R. Arterioscler. Thromb. Vasc. Biol. 2005, 25, 704.

16. Penning, T. D.; Khilevich, A.; Chen, B. B.; Russell, M. A.; Boys, M. L.; Wang, Y.; Duffin, T.; Engleman, V. W.; Finn, M. B.; Freeman, S. K.; Hanneke, M. L.; Keene, J. L.; Klover, J. A.; Nickols, G. A.; Nickols, M. A.; Rader, R. K.; Settle, S. L.; Shannon, K. E.; Steininger, C. N.; Westlin, M. M.; Westlin, W. F. Bioorg. Med. Chem. Lett. 2006, 16, 3156.

17. .Sharp, S. Y.; Boxall, K.; Rowlands, M.; Prodromou, C.; Roe, S. M.; Maloney, A. Powers, M.; Clarke, P. A.; Box, G.; Sanderson, S.; Patterson, L.; Matthews, T. P.; Cheung, K. M.; Ball, K.; Hayes, A.; Raynaud, F.; Marais, R.; Pearl, L.; Eccles, S.; Aherne, W.; McDonald, E.; Workman, P. Cancer Res. 2007, 67, 2206.

18. Wasylyk, C.; Zheng, H.; Castell, C.; Debussche, L.; Multon, M. C.; Wasylyk, B. Cancer Res. 2008, 68, 1275.

19. Liekens, S.; Hernández, A. I.; Ribatti, D.; De Clercq, E.; Camarasa, M. J.; PérezPérez, M. J.; Balzarini, J. J. Biol. Chem. 2004, 279, 29598. 